\title{
Talking in the present, caring for the future: Language and environment ${ }^{\text {th }}$
}

\author{
Astghik Mavisakalyan ${ }^{*, a, b}$, Yashar Tarverdi ${ }^{\mathrm{a}, 1}$, Clas Weber ${ }^{\mathrm{c}, 2}$ \\ ${ }^{a}$ Bankwest Curtin Economics Centre, Curtin Business School, Curtin University, Australia \\ ${ }^{\mathrm{b}}$ ARC Centre of Excellence for the Dynamics of Language, Australia \\ ${ }^{\mathrm{c}}$ Department of Philosophy, University of Western Australia, Australia
}

\section{A R T I C L E I N F O}

\section{Keywords:}

Language

Linguistic relativity

Intertemporal preference

Climate change

Environmental policy

JEL classification:

D83

Q54

Q58

Z13

\begin{abstract}
A B S T R A C T
This paper identifies a new source that explains environmental behaviour: the presence of future tense marking in language. We predict that languages that grammatically mark the future affect speakers' intertemporal preferences and thereby reduce their willingness to address environmental problems. We first show that speakers of languages with future tense marking are less likely to adopt environmentally responsible behaviours and to support policies to prevent environmental damage. We then document that this effect holds across countries: future tense marking is an important determinant of climate change policies and global environmental cooperation. The results suggest that there may be deep and surprising obstacles for attempts to address climate change.
\end{abstract}

\section{Introduction}

This paper provides a novel explanation for differences in environmental behaviour within and across countries: future tense marking in language. Language is important for economic outcomes for two reasons. First, language may serve as a marker of underlying cultural factors. It has been shown that future tense is associated with speakers' long-term orientation (Galor et al., 2016); long-term orientation in turn is relevant for a range of economic outcomes. Second, language may have a direct effect on cognition and behaviour. This effect has been documented in a nascent, but rapidly growing economics literature on the link between linguistic structures and economic outcomes (see Mavisakalyan and Weber, 2017 for a review). Part of this literature builds on the so-called Linguistic Relativity Hypothesis to propose that the structure of our language affects our thinking and behaviour.

Speakers of languages that lack future tense marking speak about future events in the present tense, i.e. as if they were present. In contrast, languages with future tense marking require speakers to use a distinct form when talking about the future. This linguistic

\footnotetext{
We thank Siobhan Austen, Steven Bond-Smith, Felix Chan, Alan Duncan, Robert Durand, Nick Evans, Jerg Gutmann, Mark Harris, Mariko Klasing, Robbert Maseland, Petros Milionis, Anna Minasyan, Lee Smales and the participants of seminars at Curtin University and University of Groningen and the 46th Australian Conference of Economists for valuable comments. Suggestions by two anonymous referees and the editor have led to significant improvement of the paper. Mavisakalyan gratefully acknowledges the hospitality of Norwegian Social Research (NOVA) where a part of this study was completed.

* Corresponding author at: GPO Box U1987, Perth WA 6845, Australia.

E-mail addresses: astghik.mavisakalyan@curtin.edu.au (A. Mavisakalyan), yashar.tarverdi@curtin.edu.au (Y. Tarverdi), clas.weber@uwa.edu.au (C. Weber).

${ }^{1}$ Postal address: GPO Box U1987, PerthWA 6845, Australia.

2 Postal address: 35 Stirling Highway, CrawleyWA 6009, Australia.
} 
difference seems to affect speakers' intertemporal preferences and induces less future-oriented behaviour (Chen, 2013). ${ }^{3}$ Consistent with this hypothesis, recent studies have shown that speakers of languages with future tense marking save less and invest less in their health (Chen, 2013; Guin, 2015). At the corporate level, the existing evidence suggests that firms in locations with future tense marking have lower precautionary cash holdings (Chen et al., 2015) and invest less in research and development (Su et al., 2016). That intertemporal preferences potentially mediate the effects of grammatical future tense has been shown experimentally through elicited time preference data by Sutter et al. (2015). Our study contributes to this literature by extending the effects of future tense marking to a new and highly significant area of future oriented-behaviour: environmental action.

The literature has studied several determinants of individual environmental action, highlighting the role of both economic factors and norms (Inglehart, 1995; Gelissen, 2007; Franzen and Meyer, 2010; Bechtel et al., 2016). Existing studies on policies concerning climate change and other environmental problems focus mainly on countries' economic (Damania et al., 2003; Damania and Fredriksson, 2003), institutional (Congleton, 1992; Fredriksson and Neumayer, 2013), historical (Fredriksson and Wollscheid, 2015; Ang and Fredriksson, 2017) and demographic (Tonn et al., 2001; Kahn, 2002) traits. To the best of our knowledge, our study is the first to combine the analysis of the determinants of environmental actions and policies with the study of linguistic structures in economics, and to identify future time reference in language as a significant source of variation in environmental action within and across countries.

We use individual-level data from the World Values Surveys to demonstrate that individual speakers of languages with obligatory future tense marking are less likely to adopt environmentally responsible behaviours compared to observationally identical individuals who speak languages that do not grammatically distinguish between present and future. Moreover, we show that they are also less likely to support policies to prevent environmental damage. We complement the individual-level analysis with an analysis of environmental policy outcomes across countries. The results of this analysis are consistent with those obtained in individual-level comparisons: countries similar in their economic, demographic and institutional characteristics, yet different in their grammatical structure have different climate change policies and global environmental cooperation outcomes. Policies are less stringent in places where the majority language requires future tense marking.

We first provide some background on the connection between culture, language and behaviour and propose mechanisms which mediate the effect of language on climate change action (Section 2). In Section 3 we describe the data used in the study, followed by a discussion of empirical approaches in Section 4. Section 5 presents the results, including various robustness checks. We conclude with a discussion of the implications of our findings in Section 6.

\section{Background}

\subsection{Language, culture and behaviour}

The relationship between language, culture, and behaviour is complex. First, many features of language are determined by culture. Culture, in the form of inherited beliefs and values, has in turn important effects on behaviour. Viewed in this way, linguistic structures serve as indicators of cultural variables. Second, there is good evidence that language also has a direct influence on cognition and behaviour - the way we speak seems to affect the way we think and act. Finally, there are reciprocal connections between language and culture: language may support the influence and preservation of culture by aiding its propagation and giving it a lasting form; language may further shape culture, as it is the main medium of its transmission (Mavisakalyan and Weber, 2017).

The idea that there's a direct influence of language on cognition and behaviour is at the heart of the Linguistic Relativity Hypothesis (LRH). In a nutshell, the LRH states that the structure of one's language has a systematic influence on cognition and behaviour. ${ }^{4}$ Different languages represent the world in different ways by emphasising different aspects of reality. As a result, speakers of a certain language may be more sensitive to various features of the world. For example, Russian has different basic colour terms than English: it has one basic term for light blue and another one for dark blue, but none corresponding to the generic "blue". It thus forces its speakers to distinguish light from dark blue. Experiments show that Russian speakers are better at perceptually discriminating different shades of blue as a consequence (Winawer et al., 2007). For decades, linguists and cognitive scientists have regarded the LRH as misguided. However, starting in the early 1990s, the theory has received a revival, and there is now a substantial and evergrowing body of literature that testifies to its validity (e.g. Levinson, 1996; Boroditsky et al., 2003; Slobin, 2003; Kay and Regier, 2006; Levinson and Wilkins, 2006).

\footnotetext{
${ }^{3}$ The literature has additionally considered the effects of two other linguistic features. Linguistic gender systems have been linked with gender inequalities in various contexts including the labour market (Mavisakalyan, 2015; Gay et al., 2017), corporate and political leadership (Santacreu-Vasut et al., 2014; Hicks et al., 2016), household division of labour (Hicks et al., 2015), education (Davis and Reynolds, 2016) and health (Bhalotra et al., 2015). Grammatical rules governing personal pronouns (pronoun drop and politeness distinctions) have been linked to various cultural traits across countries, including individualism vs collectivism, social distance, etc. (Kashima and Kashima, 1998; Davis and Abdurazokzoda, 2016). Furthermore, studies have exploited these grammatical features to study the causal relationship between culture and various socio-economic outcomes (Licht et al., 2007; Tabellini, 2008; Davis and Williamson, 2016).

${ }^{4}$ For an overview on the LRH see Gumperz and Levinson (1996); Lucy (1997); Casasanto (2015). There are different interpretations of the LRH (Scholz et al., 2016). A strong interpretation assumes a strong effect of language on thought: language determines thought; i.e. no thought (of a certain type) without corresponding linguistic structures. A moderate interpretation assumes only a moderate effect of language on thought: language influences thought in systematic and non-trivial ways. The existing evidence on the LRH supports moderate readings of the LRH better than strong ones. Here, we are only assuming a moderate interpretation.
} 


\subsection{Future tense, long-term orientation, and temporal displacement}

Tense marking is a linguistic feature that seems to affect economic outcomes (Chen, 2013). In particular, the way a language organises reference to the future seems to have consequences for a number of future-directed actions, such as saving, exercising, abstaining from smoking, condom use, retirement savings, and long-run health (Chen, 2013). In some languages, e.g. French and English, speakers are required to use a dedicated form when talking about future events. In other languages, e.g. German and Finnish, speakers can talk about the future in the same grammatical form in which they talk about the present. ${ }^{5}$

English: Tomorrow they will auxiliary drive to Paris.

French: Demain ils conduiront à Paris - (Tomorrow they drive future $_{\text {to Paris). }}$

German: Morgen fahren sie nach Paris - (Tomorrow they drive present to Paris).

We follow the terminology and classification of Chen (2013) in referring to languages which require a dedicated marking of the future as strong-FTR languages (e.g. English, French) and to languages that do not require to grammatically mark the future as weakFTR languages (e.g. German, Finnish). ${ }^{6}$ The grammatical difference between strong- and weak-FTR is associated with agents' intertemporal preferences and decision making. Our study suggests that this influence includes environmental behaviour.

According to the above, there are two ways to understand the influence of future tense on speakers' intertemporal preferences and behaviour (both are consistent with our findings). Future tense may be a marker for cultural factors, or future tense may directly affect speakers' cognition and behaviour (or both). Both the cultural and the linguistic-cognitive channel of influence rely on the phenomenon of temporal discounting. Humans (and other animals) have a well-established tendency to discount future costs and rewards (Ramsey, 1928; Solnick et al., 1980; Kirby and Herrnstein, 1995; Frederick et al., 2002). The further in the future an outcome seems, the more we discount its potential costs or benefits.

The mechanism associated with the cultural channel may proceed via speakers' orientation towards the future. Absence of grammatical future tense in a language seems to indicate increased long-term orientation among its speakers (Galor et al., 2016). Increased long-term orientation can be represented by its effect on agents' discount rates. Different agents differ in how strongly the effect of temporal discounting is manifested, as measured by different discount rates. We can thus understand the effect of long-term orientation as a reduction in agents' discount rates. Speakers of strong-FTR language have higher discount rates compared to speakers of weak-FTR languages.

The mechanism associated with the linguistic-cognitive channel combines temporal discounting with temporal displacement. The idea behind temporal displacement is that using a dedicated grammatical form to talk about future events subjectively projects these events further away from the speaker's now - they appear temporally more distant to the agent. The separate grammatical form represents the future as discontinuous with the present. Conversely, speaking about the future in the present tense depicts it as continuous with the present and subjectively locates future outcomes closer to the agent's current temporal perspective. The effect of temporal displacement then combines with that of temporal discounting. In tandem, temporal displacement and temporal discounting affect agents' intertemporal preference structure such that future options appear less rewarding and less costly to speakers of a strong-FTR languages, compared to speakers of weak-FTR languages, since they appear temporally more distant, and are thus more strongly affected by temporal discounting. ${ }^{7}$

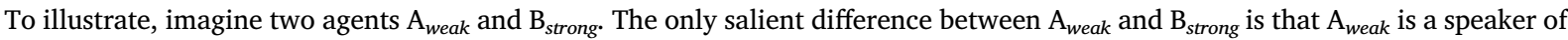
a weak-FTR language, presenting the future as if it were present and indicating high long-term orientation, whereas $B_{\text {strong }}$ is a speaker of a strong FTR language, projecting the future away from the present and marking low long-term orientation. Assume that $\mathrm{A}_{\text {weak }}$ is indifferent between a present reward $\mathrm{x}_{1}$ and an intrinsically more rewarding future option $\mathrm{x}_{2}$ : $\left(\mathrm{x}_{1}, \mathrm{t}_{\text {now }}\right)=\left(\mathrm{x}_{2}, \mathrm{t}_{\text {later }}\right)$. When $\mathrm{B}_{\text {strong }}$ is presented with the same choice, $\mathrm{s} /$ he may well prefer the less rewarding present option. There are two potential explanations. First, the presence of future tense may indicate that B's long-term orientation is low, and thus her discount rate is high: $\delta_{A}<\delta_{B}$. Second, assuming that temporal displacement is operative, the later option appears comparatively more distant and therefore less attractive (even assuming identical discount rates). Again, it is possible that both mechanism are jointly operative. Both mechanisms influence B's intertemporal preference structure such that: $\left(\mathrm{x}_{1}, \mathrm{t}_{\text {now }}\right)>\left(\mathrm{x}_{2}, \mathrm{t}_{\text {later }}\right)$.

\subsection{Intertemporal preferences and environmental action}

Pro-environmental actions and policies typically incur present costs for the sake of future rewards. For instance, green products are on average more expensive than conventional products. Buying a green product thus has significant short-term costs, but the expected reward, i.e. avoiding damaging environmental outcomes, is located relatively far in the future. The pay-off structure of such decisions thus makes them amenable to the above described influence of temporal displacement and discounting. Speakers of weakFTR languages are expected to value the future benefits of pro-environmental actions and policies higher than speakers of strong FTR languages. Given their different preferences, speakers of weak-FTR languages are expected to engage in more pro-environmental

\footnotetext{
${ }^{\mathbf{5}}$ It is true that German, like English, also has the potential to explicitly mark reference to the future, e.g. with the auxiliary "werden". It is therefore important to stress that the difference between the two groups of languages concerns whether future time reference "is overtly and obligatorily marked" (Dahl, 2000, p. 310, our emphasis).

${ }^{6}$ Chen's (2013) classification is based on that of the European Science Foundation's Typology of Languages in Europe (EUROTYP) project (Dahl, 2000), which undertook a very comprehensive study of the tense and aspect system of the major European languages.

${ }^{7}$ It is also conceivable that future tense has a direct effect on speakers' discount rates; in that case the cultural and the linguistic-cognitive channel work in equivalent ways. The mechanism proposed here is very similar to one of several proposed in Chen (2013, p. 695).
} 
behaviour than speakers of strong-FTR language. This is indeed what our study finds.

Furthermore, in a standard median voter model, which assumes the presence of electoral motives, political decisions reflect the preferences of the electorate (Downs, 1957). Hence, given the different intertemporal preferences of individual voters, we expect to see better environmental policy and cooperation outcomes in places with weak-FTR languages. The same result is predicted if we alternatively assume a 'citizen candidates' model. Politicians who speak weak-FTR languages have either higher long-term orientation and a correspondingly reduced temporal discount rate or a general tendency to perceive future concerns as more pressing (or a combination of both). As a result, they have stronger pro-environmental preferences and are more likely to implement policies consistent with those preferences once elected (Osborne and Slivinski, 1996; Besley and Coate, 1997). Both scenarios are consistent with our findings; distinguishing between them is beyond the scope of our paper.

\section{Data}

Most of the empirical evidence on the determinants of environmental policies are based on large country-level datasets (e.g., Damania et al., 2003; Fredriksson and Neumayer, 2013; Fredriksson and Wollscheid, 2015; Ang and Fredriksson, 2017). Crosscountry data provide a general picture, but they may conceal important behavioural mechanisms underlying aggregate outcomes. Yet, not all questions are amenable to sub-national analysis; understanding the drivers of climate change policies is particularly difficult using micro-level data. With these considerations in mind, the paper combines an individual-level analysis that employs survey data from a large sample of countries to compare pro-environmental behaviours of individuals with aggregate-level data to perform cross-country comparisons of climate change policies.

\subsection{Measurement of FTR}

Our classification of languages into those which require a dedicated marking of the future, strong-FTR languages, and those that do not, weak-FTR languages, is based on data from Chen (2013). Chen's classification rests on whether a language requires an obligatory FTR in 'prediction-based contexts' adopted from the European Science Foundation's Typology of Languages in Europe (EUROTYP) project (Dahl, 2000). To justify this criterion, Dahl (2000) notes that "whether FTR is overtly and obligatorily marked in predictionbased sentences can be used as one of the major criteria for whether it is grammaticalized in language or not" (Dahl, 2000, p. 310). The data itself comes from EUROTYP and, in the case of non-European languages, other established cross-linguistic analyses (e.g., Dahl and Dienes, 1984; Dahl, 1985; Bybee et al., 1994; Nurse, 2008; Cyffer et al., 2009) (see Appendix B in Chen (2013) for further discussion on the coding of languages). Chen (2013) further substantiates the validity of this measure using frequency analysis of future-marking in weather forecast texts retrieved from the web. ${ }^{8}$

\subsection{Individual-level data}

The data source for individual-level analysis of pro-environmental behaviour is the World Values Surveys, a collection of nationally representative, individual-level surveys conducted in nearly 100 countries (almost 90 percent of the world's population) containing rich information on a variety of attitudes and preferences, as well as standard socio-economic and demographic characteristics of individuals. Six waves of the survey, with the latest covering the years 2010-2014, have been conducted since its inception in 1981-1984. Cross-country comparability, representativeness, richness and relevance of the data make WVS highly appropriate for the purposes of individual-level analysis in this study. ${ }^{9}$

The language FTR measure is linked to the language spoken at home by the individual. This information has been collected since wave 3 conducted in years 1995-1998. The FTR of the language spoken by individuals is connected to their pro-environmental behaviour, ENVIRONMENTAL ACTION, as captured by affirmative responses to a question on whether in the preceding 12 months, 'out of concern for the environment', they have chosen household products that they think are better for the environment. Capturing individuals' willingness to incur short-term costs for the sake of future rewards, this measure is highly appropriate for understanding individual support for climate change policies adopted at national level. This question was asked in wave 3 of WVS conducted in years 1995-1998. The study therefore is restricted to this wave. As a second dependent variable, we utilise information on the respondents' support to increase taxes if the extra money is used to prevent environmental damage and their willingness to buy things at $20 \%$ higher than usual prices to construct a binary measure of their WILLINGNESS TO PAY FOR POLICIES.

Following Chen (2013), our analysis excludes first-generation immigrants to isolate the effect of differences in language from native-immigrant differences. We drop observations with missing outcome data, arriving at a baseline sample of 34,461 individuals in 35 countries. $^{10}$

\footnotetext{
${ }^{8}$ The sample of languages from this analysis is too small to be useful for the current study.

${ }^{9}$ An alternative approach to individual-level analysis of the effect of language structures on economic outcomes of individuals is to study the behaviour of immigrants (e.g., Hicks et al., 2015; Gay et al., 2017) within a single immigrant-hosting country, applying an 'epidemiological approach' (see e.g. Gay et al., 2016 for a discussion). We were not able to identify a data source that would contain appropriate information on pro-environmental behaviours and languages spoken by individuals to allow for such study.

${ }^{10}$ The countries in the sample include: Albania, Azerbaijan, Australia, Armenia, Bosnia \& Herzegovina, Bulgaria, Belarus, Chile, China, Czech Republic, Estonia, Finland, Georgia, Germany, India, Latvia, Lithuania, Macedonia, Mexico, Montenegro, New Zealand, Nigeria, Peru, Puerto Rico, Romania, Russian Federation, Serbia, Slovak Republic, South Africa, Spain, Sweden, Taiwan, United States, Uruguay, Venezuela.
} 
Table 1

Individual-level descriptive statistics.

\begin{tabular}{|c|c|c|c|}
\hline \multirow[t]{2}{*}{ Variables } & \multicolumn{3}{|l|}{$\begin{array}{l}\text { Mean } \\
\text { (s.d.) }\end{array}$} \\
\hline & WEAK FTR & STRONG FTR & All \\
\hline STRONG FTR & 0 & 1 & $\begin{array}{l}0.869 \\
(0.338)\end{array}$ \\
\hline ENVIRONMENTAL ACTION & $\begin{array}{l}0.617 \\
(0.486)\end{array}$ & $\begin{array}{l}0.411 \\
(0.492)\end{array}$ & $\begin{array}{l}0.438 \\
(0.496)\end{array}$ \\
\hline MALE & $\begin{array}{l}0.500 \\
(0.500)\end{array}$ & $\begin{array}{l}0.477 \\
(0.499)\end{array}$ & $\begin{array}{l}0.480 \\
(0.500)\end{array}$ \\
\hline AGE & $\begin{array}{l}40.840 \\
(14.920)\end{array}$ & $\begin{array}{l}40.990 \\
(15.980)\end{array}$ & $\begin{array}{l}40.970 \\
(15.850)\end{array}$ \\
\hline MARRIED & $\begin{array}{l}0.721 \\
(0.448)\end{array}$ & $\begin{array}{l}0.643 \\
(0.479)\end{array}$ & $\begin{array}{l}0.653 \\
(0.476)\end{array}$ \\
\hline NO CHILDREN & $\begin{array}{l}0.252 \\
(0.434)\end{array}$ & $\begin{array}{l}0.260 \\
(0.439)\end{array}$ & $\begin{array}{l}0.259 \\
(0.438)\end{array}$ \\
\hline PRIMARY & $\begin{array}{l}0.286 \\
(0.452)\end{array}$ & $\begin{array}{l}0.196 \\
(0.397)\end{array}$ & $\begin{array}{l}0.208 \\
(0.406)\end{array}$ \\
\hline SECONDARY & $\begin{array}{l}0.284 \\
(0.451)\end{array}$ & $\begin{array}{l}0.307 \\
(0.461)\end{array}$ & $\begin{array}{l}0.304 \\
(0.460)\end{array}$ \\
\hline TERTIARY & $\begin{array}{l}0.430 \\
(0.495)\end{array}$ & $\begin{array}{l}0.497 \\
(0.500)\end{array}$ & $\begin{array}{l}0.488 \\
(0.500)\end{array}$ \\
\hline EMPLOYED & $\begin{array}{l}0.692 \\
(0.462)\end{array}$ & $\begin{array}{l}0.514 \\
(0.500)\end{array}$ & $\begin{array}{l}0.537 \\
(0.499)\end{array}$ \\
\hline INCOME DECILE 1 & $\begin{array}{l}0.077 \\
(0.268)\end{array}$ & $\begin{array}{l}0.127 \\
(0.333)\end{array}$ & $\begin{array}{l}0.121 \\
(0.326)\end{array}$ \\
\hline INCOME DECILE 2 & $\begin{array}{l}0.105 \\
(0.307)\end{array}$ & $\begin{array}{l}0.174 \\
(0.379)\end{array}$ & $\begin{array}{l}0.165 \\
(0.371)\end{array}$ \\
\hline INCOME DECILE 3 & $\begin{array}{l}0.136 \\
(0.343)\end{array}$ & $\begin{array}{l}0.151 \\
(0.358)\end{array}$ & $\begin{array}{l}0.149 \\
(0.356)\end{array}$ \\
\hline INCOME DECILE 4 & $\begin{array}{l}0.149 \\
(0.356)\end{array}$ & $\begin{array}{l}0.129 \\
(0.335)\end{array}$ & $\begin{array}{l}0.132 \\
(0.338)\end{array}$ \\
\hline INCOME DECILE 5 & $\begin{array}{l}0.169 \\
(0.375)\end{array}$ & $\begin{array}{l}0.114 \\
(0.317)\end{array}$ & $\begin{array}{l}0.121 \\
(0.326)\end{array}$ \\
\hline INCOME DECILE 6 & $\begin{array}{l}0.123 \\
(0.329)\end{array}$ & $\begin{array}{l}0.084 \\
(0.278)\end{array}$ & $\begin{array}{l}0.089 \\
(0.285)\end{array}$ \\
\hline INCOME DECILE 7 & $\begin{array}{l}0.094 \\
(0.292)\end{array}$ & $\begin{array}{l}0.074 \\
(0.262)\end{array}$ & $\begin{array}{l}0.077 \\
(0.267)\end{array}$ \\
\hline INCOME DECILE 8 & $\begin{array}{l}0.063 \\
(0.243)\end{array}$ & $\begin{array}{l}0.062 \\
(0.240)\end{array}$ & $\begin{array}{l}0.062 \\
(0.241)\end{array}$ \\
\hline INCOME DECILE 9 & $\begin{array}{l}0.038 \\
(0.190)\end{array}$ & $\begin{array}{l}0.046 \\
(0.209)\end{array}$ & $\begin{array}{l}0.045 \\
(0.207)\end{array}$ \\
\hline INCOME DECILE 10 & $\begin{array}{l}0.046 \\
(0.208)\end{array}$ & $\begin{array}{l}0.038 \\
(0.192)\end{array}$ & $\begin{array}{l}0.039 \\
(0.194)\end{array}$ \\
\hline $\mathrm{N}$ & 4528 & 29,933 & 34,461 \\
\hline
\end{tabular}

Note. - Standard deviations in parentheses. Variables are defined in section 3.2. Source: World Values Survey Wave 3 (1995-1998). The sample is restricted to non-immigrants. Thirty-five countries listed in footnote 10 are included.

Table 1 provides the definitions and descriptive statistics for all variables used in the baseline analysis by language FTR. Eightyseven percent of individuals in the sample speak a strong FTR language. The incidence of ENVIRONMENTAL ACTION is $62 \%$ among speakers of weak FTR languages and 41\% among speakers of strong FTR languages suggesting a negative effect of sTRONG FTR on pro-environmental action.

The individual-level analysis controls for standard observable demographic and socio-economic characteristics of individuals included in similar studies (e.g., Gelissen, 2007; Franzen and Meyer, 2010; Bechtel et al., 2016). The demographic controls include gender, age and family circumstances. Forty-eight percent of individuals in the sample are male-a gender that has been linked to unecological attitudes (Blocker and Eckberg, 1997; Gelissen, 2007). We control for age, to account for associated differences in environmental preferences. As Farzin and Bond (2006) argue, young people may have larger stakes in environmental quality, and therefore may have stronger demand for stringent environmental policies. On the other hand, older people may feel the environmentally induced health problems more directly, and thus may be more willing to extend support for such policies. Intergenerational environmental altruism and greater access to time and resources to support environmental initiatives may further contribute to higher demand for environmental policies by older people (Farzin and Bond, 2006). Intergenerational altruism is also more likely to be observed among those with families and children-additional characteristics of individuals we control for. The average age in the sample is around 41 years old; sixty-five percent of individuals are married and only $26 \%$ of all individuals have no children.

Furthermore, we account for standard socio-economic characteristics of individuals. These include educational attainment 
expected to be positively correlated with pro-environmental behaviour (e.g., Gelissen, 2007; Franzen and Meyer, 2010). Primary and secondary school attainment comprise $21 \%$ and $30 \%$ of the sample, with the remaining $49 \%$ having tertiary education. We further control for individuals' employment status (54\% prevalence in the sample) and income, captured in deciles, both expected to result in increased propensity for environmental action (e.g., Franzen and Meyer, 2010; Bechtel et al., 2016).

We complement the individual-level analysis of pro-environmental behaviour with a cross-country analysis of environmental policies. The data used in this analysis are described next.

\subsection{Country-level data}

The cross-country analysis is based on data from multiple sources, including Steves et al. (2011); Keefer (2012); Chen (2013); Marshall et al. (2016); World Bank (2016). Together, they result in a sample of 68 countries in the baseline specification. ${ }^{11}$ Table 2 specifies the sources and presents descriptive statistics for all variables used in the baseline cross-country analysis by weak- and strong-FTR language groups. Following other studies (e.g., Licht et al., 2007; Santacreu-Vasut et al., 2013; Bhalotra et al., 2015), the FTR marker is assigned to a country's most widely spoken language (based on information collected by Alesina et al., 2003 ). ${ }^{12} 76 \%$ of the countries in our baseline sample speak a strong-FTR language, while the remaining $24 \%$ are weak-FTR countries.

We analyse the relationship between the FTR system of a country's majority language and its climate change policies as captured by Climate Laws, Institutions and Measures Index (CLIMI) developed by Steves et al. (2011) and used in several published studies (e.g., Fredriksson and Neumayer, 2013; 2016). CLIMI measures countries' climate change mitigation policies with reference to the 2005-2010 annual national communications to the UNFCCC. CLIMI uses 12 components, grouped into four key policy areas, with sub-weights and weights reflecting the contribution of each of the components/areas to climate change mitigation: (i) International cooperation (0.1) [components: Kyoto ratification (0.5), Joint Implementation or Clean Development Mechanism host (0.5)]; (ii) domestic climate framework (0.4) [components: cross-sectoral climate change legislation (0.33), carbon emissions target (0.33), dedicated climate change institution (0.33)]; (iii) significant sectoral fiscal or regulatory measures or targets (0.4) [components: energy supplies/renewables (0.3), transport (0.13), buildings (0.07), agriculture (0.13), forestry (0.17), industry (0.2)]; and (iv) additional cross-sectoral fiscal or regulatory measures (0.1) [components: cross-sectoral policy measures (1)]. CLIMI ranges from 0 and 1 , with higher values representing stricter policies.

As a second dependent variable, we use a measure of a country's participation in global collaborative environmental efforts, GLOBAL, that comes from Esty et al. (2005) and has been used in several studies on the subject (e.g., Fredriksson and Neumayer, 2013; 2016). This measure combines information on a country's number of memberships in environmental intergovernmental organizations, its contribution to international and bilateral funding of environmental projects and development aid, and its participation in international environmental agreements. GLOBAL ranges from -1.69 to 1.74 (see Esty et al., 2005 for details).

Table 2 presents the descriptive statistics for the variables employed in the baseline analysis. The average CLIMI score in the entire sample is $0.412 .^{13}$ In the sample of countries with a weak-FTR majority language it is 0.517 , while in the sample of countries with a strong-FTR language it is 0.380 . This gap of 0.137 points suggests a negative effect of STRONG FTR on CLIMI.

Our analysis of the link between language FTR and climate change policies controls for a range of observable characteristics of countries that have been accounted for in previous studies on determinants of environmental policies. Since CLIMI is derived from information collected over the period 2005-2010, we use explanatory variables averaged over this time period.

Four groups of covariates are included in the baseline models. The first included economic characteristics. We expect the demand for environmental quality to increase with GDP PER CAPITA (measured in log) (e.g., Fredriksson and Neumayer, 2013; 2016). Following these studies, we also control for opENNESs, defined as imports plus exports divided by GDP. On the one hand, more open countries may cooperate more on environmental problems (Neumayer, 2002). On the other hand, it is possible that the interests of exporting countries are threatened by environmental agreements. Under such a scenario, higher openness for trade may decrease the willingness to commit to stringent environmental policies. The sectoral structure of an economy may also influence the stringency of its environmental policies. We include manufacturing value added as a percentage of GDP, MANUFACTURING \%, to account for this possibility. According to Cole et al. (2006) and Fredriksson and Vollebergh (2009), this measure may capture the lobbying pressures from workers in the manufacturing sector for lower regulations. Alternatively, it may measure the degree to which an economy consists of pollution-intensive manufacturing, positively affecting the regulatory stringency.

The second group of covariates encompasses demographic characteristics of countries. We control for the size of the country, as captured by the log of its population size, Population size (e.g., Fredriksson and Wollscheid, 2014). Additionally, we control for the share of immigrants in the total population, IMMIGRANT \% (averaging at $8.2 \%$ in the sample) as a measure of ethnic diversity. Previous research has highlighted the difficulty in agreeing on public goods and policies in diverse societies (e.g., Easterly and Levine, 1997; Alesina et al., 1999). Accounting for ethnic diversity is particularly important in the present context, given our interest in isolating the

\footnotetext{
${ }^{11}$ The countries in the sample include: Albania, Argentina, Armenia, Australia, Austria, Azerbaijan, Bahrain, Belarus, Belgium, Bolivia, Bosnia \& Herzegovina, Brazil, Bulgaria, Canada, Colombia, Congo Republic, Costa Rica, Czech Republic, Denmark, Dominican Republic, Egypt, Estonia, Fiji, Finland, France, Georgia, Germany, Greece, Hungary, Iceland, India, Indonesia, Ireland, Italy, Japan, Jordan, Korea Republic, Kyrgyz Republic, Latvia, Lithuania, Macedonia, Madagascar, Malta, Mauritania, Mexico, Mongolia, Morocco, New Zealand, Niger, Norway, Peru, Poland, Portugal, Romania, Russian Federation, Saudi Arabia, Slovak Republic, Slovenia, South Africa, Spain, Sweden, Switzerland, Turkey, United Kingdom, United States, Uruguay, Venezuela, Vietnam.

12 To reflect the heterogeneity in multilingual countries, a weighted measure with weights given by the share of the population speaking each language is used in robustness checks (e.g., Tabellini, 2008; Mavisakalyan, 2015).

${ }^{13}$ Saudi Arabia has the lowest CLIMI score in the sample at 0.023 , while the UK has the highest score at 0.801 .
} 
Table 2

Cross-country descriptive statistics.

\begin{tabular}{|c|c|c|c|c|}
\hline \multirow[t]{2}{*}{ Variables } & \multirow[t]{2}{*}{ Source } & \multicolumn{3}{|l|}{$\begin{array}{l}\text { Mean } \\
\text { (s.d.) }\end{array}$} \\
\hline & & WEAK FTR & STRONG FTR & All \\
\hline STRONG FTR & Chen (2013) & 0 & 1 & $\begin{array}{l}0.765 \\
(0.427)\end{array}$ \\
\hline CLIMI & Steves et al. (2011) & $\begin{array}{l}0.517 \\
(0.253)\end{array}$ & $\begin{array}{l}0.380 \\
(0.205)\end{array}$ & $\begin{array}{l}0.412 \\
(0.223)\end{array}$ \\
\hline GDP PER CAPITA & World Bank (2016) & $\begin{array}{l}9.968 \\
(1.109)\end{array}$ & $\begin{array}{l}9.619 \\
(0.854)\end{array}$ & $\begin{array}{l}9.701 \\
(0.923)\end{array}$ \\
\hline OPENNESS & World Bank (2016) & $\begin{array}{l}0.943 \\
(0.312)\end{array}$ & $\begin{array}{l}0.842 \\
(0.439)\end{array}$ & $\begin{array}{l}0.865 \\
(0.413)\end{array}$ \\
\hline MANUFACTURING \% & World Bank (2016) & $\begin{array}{l}16.048 \\
(6.157)\end{array}$ & $\begin{array}{l}15.651 \\
(5.050)\end{array}$ & $\begin{array}{l}15.744 \\
(5.285)\end{array}$ \\
\hline POPULATION SIZE & World Bank (2016) & $\begin{array}{l}15.857 \\
(1.761)\end{array}$ & $\begin{array}{l}16.534 \\
(1.561)\end{array}$ & $\begin{array}{l}16.375 \\
(1.623)\end{array}$ \\
\hline IMMIGRANT \% & World Bank (2016) & $\begin{array}{l}8.647 \\
(7.143)\end{array}$ & $\begin{array}{l}8.048 \\
(10.167)\end{array}$ & $\begin{array}{l}8.189 \\
(9.496)\end{array}$ \\
\hline POPULATION AGE $65+\%$ & World Bank (2016) & $\begin{array}{l}12.793 \\
(6.524)\end{array}$ & $\begin{array}{l}10.594 \\
(5.112)\end{array}$ & $\begin{array}{l}11.111 \\
(5.505)\end{array}$ \\
\hline DEMOCRACY & Marshall et al. (2016) & $\begin{array}{l}0.750 \\
(0.447)\end{array}$ & $\begin{array}{l}0.692 \\
(0.466)\end{array}$ & $\begin{array}{l}0.706 \\
(0.459)\end{array}$ \\
\hline OTHER REGIME & Marshall et al. (2016) & $\begin{array}{l}0.250 \\
(0.447)\end{array}$ & $\begin{array}{l}0.308 \\
(0.466)\end{array}$ & $\begin{array}{l}0.294 \\
(0.459)\end{array}$ \\
\hline LEFT GOVERNMENT & Keefer (2012) & $\begin{array}{l}0.375 \\
(0.500)\end{array}$ & $\begin{array}{l}0.250 \\
(0.437)\end{array}$ & $\begin{array}{l}0.279 \\
(0.452)\end{array}$ \\
\hline CONTINENT AFRICA & World Bank (2016) & $\begin{array}{l}0.125 \\
(0.342)\end{array}$ & $\begin{array}{l}0.096 \\
(0.298)\end{array}$ & $\begin{array}{l}0.103 \\
(0.306)\end{array}$ \\
\hline CONTINENT ASIA & World Bank (2016) & $\begin{array}{l}0.188 \\
(0.403)\end{array}$ & $\begin{array}{l}0.212 \\
(0.412)\end{array}$ & $\begin{array}{l}0.206 \\
(0.407)\end{array}$ \\
\hline CONTINENT EUROPE & World Bank (2016) & $\begin{array}{l}0.625 \\
(0.500)\end{array}$ & $\begin{array}{l}0.423 \\
(0.499)\end{array}$ & $\begin{array}{l}0.471 \\
(0.503)\end{array}$ \\
\hline CONTINENT NORTH AMERICA & World Bank (2016) & $\begin{array}{l}0.000 \\
(0.000)\end{array}$ & $\begin{array}{l}0.096 \\
(0.298)\end{array}$ & $\begin{array}{l}0.074 \\
(0.263)\end{array}$ \\
\hline CONTINENT OCEANIA & World Bank (2016) & $\begin{array}{l}0.063 \\
(0.250)\end{array}$ & $\begin{array}{l}0.038 \\
(0.194)\end{array}$ & $\begin{array}{l}0.044 \\
(0.207)\end{array}$ \\
\hline CONTINENT SOUTH AMERICA & World Bank (2016) & $\begin{array}{l}0.000 \\
(0.000)\end{array}$ & $\begin{array}{l}0.135 \\
(0.345)\end{array}$ & $\begin{array}{l}0.103 \\
(0.306)\end{array}$ \\
\hline $\mathrm{N}$ & & 16 & 52 & 68 \\
\hline
\end{tabular}

Note. - Standard deviations in parentheses. Variables are defined in section 3.3. The countries in the sample are listed in footnote 11 .

effect of language from other confounders; including the immigrant share of the population therefore seems appropriate. Furthermore, the share of the population of 65 or more years of age, POPULATION AGE $65+\%$ (averaging at $11.1 \%$ in the sample) is included as an additional demographic control for reasons discussed above. In particular, it has been suggested that intergenerational environmental altruism, linked with older age, may contribute to pro-environmental behaviour (Farzin and Bond, 2006).

The third group of covariates comprises measures for institutions. We control for countries' political regime based on polity score measure available from the Polity IV data set (Marshall et al., 2016). The polity score captures the regime authority spectrum on a 21 point scale ranging from -10 (hereditary monarchy) to +10 (consolidated democracy), and is converted into two regime categories to distinguish between democracies $(+6$ to +10$), 71 \%$ in the sample, and other regime types (Marshall et al., 2016). A strand of literature shows that democracies are more conducive to enactment of environmental regulations compared to autocracies (e.g., Murdoch and Sandler, 1997; Farzin and Bond, 2006). As an additional control, we include an indicator for LEFT GOVERNMENT, with its prevalence being $27.9 \%$ in the sample, based on information on the political orientation of the national leader's party available from Keefer (2012). ${ }^{14}$ An implication that follows from a number of studies is that left-wing parties are more pro-environmental than their right-wing counterparts (e.g., Neumayer, 2003; 2004).

Finally, dummies for continents are included throughout the analysis. Forty-seven percent of the countries in the sample are based on the European continent, followed by $21 \%$ country representation from Asia. Africa and South America contribute each $10.3 \%$ of the countries in the sample, while North American countries comprise 7\%. The smallest share of countries in the sample, $4.4 \%$, is in Oceania.

\footnotetext{
${ }^{14}$ According to the source for this data, the parties have been classified as left if their names reveal them to be communist, socialist, or social democratic or if the sources label them as left-wing (Beck et al., 2001).
} 


\section{Empirical approach}

Our empirical analysis proceeds in several steps. We start with an analysis of individual-level determinants of pro-environmental behaviour. We then complement the individual-level analysis with an analysis of environmental policies across countries and establish a baseline effect of language FTR on policies across countries. We extend this analysis, by including additional variables that could be correlated with hitherto unexplained parts of climate change policies. Clearly, this approach cannot fully account for all confounding influences. We therefore adopt two strategies to directly address the problem of endogeneity. First, we use an instrumental variable, a source of exogenous variation in language FTR, and estimate a 2SLS model. Second, we also assess the extent of bias following the partial identification approach proposed by Oster (2016). The description of these steps follows.

\subsection{Individual-level model}

To establish the effect of STRONG FTR at the individual level, we estimate variants of a model of propensity for ENVIRONMENTAL ACTION, $E A_{j l}^{*}$ for an individual $j$ in country $l$ of the following form:

$$
E A_{j l}^{*}=K_{j l} \gamma+\zeta \text { StrongFTR } R_{j l}+\omega_{j l} \text { forall } j=1, \cdots, M ; l=1, \cdots, P
$$

where StrongFTR ${ }_{j l}$ is the indicator of a strong FTR language, $K_{j l}$ is a vector of controls for gender, age, family status, education, employment and income characteristics and $\omega_{j l}$ is a disturbance term. Observed environmental action $E A_{j l}$ is assumed to relate to latent propensity through the criterion $E A_{j l}=1\left(E A_{j l}^{*} \geq 0\right)$, which under an assumption of normality for $\omega_{j l}$ gives rise to the standard probit model of the form:

$$
\operatorname{Pr}\left(E A_{j l}=1 \mid K_{j l}, \text { StrongFTR }_{j l}\right)=\Phi\left(K_{j l} \gamma+\zeta \text { StrongFTR }_{j l}\right)
$$

with marginal effects of STRONG FTR derived from the estimated model thus:

$$
\frac{\partial \operatorname{Pr}\left(E A_{j l}=1 \mid K_{j l}, \text { StrongFTR }_{j l}\right)}{\partial \text { StrongFTR }_{j l}}=\zeta \phi\left(K_{j l} \gamma+\zeta \text { StrongFTR }_{j l}\right)
$$

Marginal effects such as those described in (3) can be evaluated either at the sample means or for specified values of each explanatory variable.

The identical model is estimated for wILLINGNESS TO PAY FOR POLICIES as dependent variable.

\subsection{Cross-country model}

To establish the baseline relationship between language FTR and climate change policy of country $i$, we estimate variants of the following model using ordinary least squares (OLS):

$$
\text { CLIMI }_{i}=X_{i} \alpha+\beta \text { StrongFTR }_{i}+\varepsilon_{i} \text { foralli } i=1, \cdots, N
$$

where StrongFTR is an indicator of strong-FTR language spoken in the country, $X_{i}$ is a vector of controls for economic, demographic, institutional and geographic characteristics of countries defined in Section 3.3, and $\varepsilon_{i}$ is a disturbance term.

Estimating the effect of language FTR on climate change policies requires that it is exogenously determined and uncorrelated with the error term in (4). However, this is unlikely to hold due to unobserved heterogeneity: both linguistic features and environmental policy outcomes may be the product of deeper, unobserved factors. ${ }^{15}$

Existing attempts to isolate the effect of linguistic measures on various economic outcomes have taken into account the historical and geographic relatedness of languages (e.g., Chen et al., 2015; Mavisakalyan, 2015; Roberts et al., 2015). We follow these approaches as a first step to mitigate the influence of unobserved heterogeneity, and include proxies for such relatedness. We sequentially introduce these proxies into the estimations of Eq. (4). The aim is to reveal the extent to which the estimated effect of STRONG FTR on CLIMI captures the correlation between STRONG FTR and these variables that have been omitted from Eq. (4), by comparing the estimated parameters from baseline and comprehensive specifications.

Despite our efforts to control for relevant observable variables, we cannot rule out that some omitted variable is correlated with both STRONG FTR and CLIMI. A conventional approach to deal with this possibility is to use an instrumental variable. Galor et al. (2016) argue that pre-industrial geographical features that resulted in high returns to agricultural investments are at the root of crosslanguage variations in the presence of future tense. Building on this observation, we use CROP YIELD (pre-1500CE), sourced from Galor and Özak (2016), as an instrument for STRONG FTR and estimate Eq. (4) using 2SLS where sTRONG FTR is treated as endogenous and modeled as:

$$
\text { StrongFTR }_{i}=\tau X_{i}+\psi \text { CropYield }_{i}+\iota_{i} \text { foralli }=1, \cdots, N
$$

To evaluate how concerned we should be about omitted variables, we also exploit an approach proposed by Oster (2016), which

\footnotetext{
${ }^{15}$ We largely exclude the possibility of reverse causality. Tabellini (2008) points out: 'As a classic example of network externalities, language evolves slowly over time. Linguistic innovations are costly because until they are widely adopted communications is more difficult.' (p. 273). In support of this, Roberts et al. (2015) show that future-time reference variable, in particular, is very stable over time.
} 
builds on the work of Altonji et al. (2005) to use the amount of selection on the observables as a guide to the amount of selection on the unobservables. To that end, we evaluate the bias-adjusted coefficient derived by Oster (2016):

$$
\beta^{*} \approx \widetilde{\beta}-\delta[\dot{\beta}-\widetilde{\beta}] \frac{R_{\max }-\widetilde{R}}{\widetilde{R}-\dot{R}}
$$

where $\dot{\beta}$ and $\dot{R}$ are the coefficient and R-squared from a parsimonious model including sTRONG FTR but no other controls, and $\widetilde{\beta}$ and $\widetilde{R}$ are the coefficient and R-squared from a regression with STRONG FTR and a set of other controls. $\delta$ denotes the relative importance of observable relative to unobservable variables in generating bias while $R_{\max }$ is the R-squared from a hypothetical regression of cLIMI on all observable and unobservable variables.

Since $\delta$ and $R_{\max }$ are not known, Oster (2016) proposes a bounding approach: the estimated effect of sTRONG FTR should range from $\widetilde{\beta}$ to $\beta^{*}$ estimated under an assumption of $\delta=1$, i.e. observables and unobservables have the same explanatory power in cLImI, and given values of $R_{\max } \in[\widetilde{R}, 1]$. We take two approaches to specifying plausible values for $R_{\max }$. First, we assume $R_{\max }=0.90$ which is sensible for a cross sectional sample that potentially has considerable noise in the outcome variable. Second, we follow Oster (2016) in setting $R_{\max }=\min \{1.3 \widetilde{R}, 1\} .{ }^{16}$ Estimated coefficients can be considered as robust, if the identified set $\left[\widetilde{\beta}, \beta^{*}\right]$ excludes zero. Furthermore, following Oster (2016), we calculate the value of $\delta$ that would be needed to explain away the entire causal effect of stronG FTR on CLIMI. Values of $\delta>1$ suggest that the results are robust, i.e. the unobservables would have to be more important than the observables in explaining cLIMI.

\section{Results}

\subsection{Individual-level results}

First, we explore the consequences of speaking a STRONG FTR language at the individual level. We estimate probit models of the effect of STRONG FTR on the probability of taking an ENVIRONMENTAL ACTION given in Eq. (2). We present the results of this analysis in Table 3. For ease of interpretation the marginal effects, such as those described in Eq. (3), are reported.

Starting with a parsimonious specification reported in column (1), we estimate a significant negative effect of sTRONG FTR language spoken at home by an individual on the probability of acting pro-environmentally. This is consistent with the descriptive statistics reported in Table 1. In column (2) we control for standard demographic and socio-economic characteristics of individuals. We estimate a negative significant marginal effect on STRONG FTR, although its magnitude is smaller. Additionally, we find that males are less likely to act pro-environmentally; this is in line with other studies (e.g., Blocker and Eckberg, 1997; Gelissen, 2007). Conversely, age is positively correlated with the probability of taking ENVIRONMENTAL ACTION. We find that the probability of acting pro-environmentally is higher for individuals who don't have children, potentially due to additional financial constraints faced by these individuals, although this result is not robust to inclusion of additional controls in subsequent models. Socio-economic characteristics are important determinants of ENVIRONMENTAL ACTION. In particular, similar to others (e.g., Gelissen, 2007; Franzen and Meyer, 2010), we find a positive link between educational attainment and the probability of acting pro-environmentally. In column (3) we repeat this regression and also include dummies for countries in the sample. The estimated marginal effect on STRONG FTR, while of considerably smaller magnitude, remains significant. Moving from a WEAK FTR to a STRONG FTR language leads to an 8.9 percentage point decrease in the probability of taking an ENVIRONMENTAL ACTION (this implies that the ENVIRONMENTAL ACTION is $20 \%$ lower). This is a sizeable effect. It is larger, for example, than that of moving from tertiary to secondary level of education, or from male to female gender identity.

In columns (4)-(6) we expand the list of control variables in an effort to mitigate the possibility of omitted variable bias in the estimates of STRONG FTR. First, we control for TRUST, a dummy that takes 1 if the respondent believes that most people can be trusted and 0 otherwise. This is a potentially important determinant of individuals' willingness to engage in action in support of a collective need. Indeed, we estimate a positive significant marginal effect on TRUST. However, the estimate on STRONG FTR is largely unaffected by the inclusion of this variable (column (4)). In column (5) we report the results of the regression that includes two further controls. The first is a dummy for LEFT VIEWS, calculated based on the individual's self-positioning on a political scale. The second is IDEALIST, a dummy that takes 1 if the respondent has the view that less emphasis on money and material possessions in the future would be a good thing and 0 otherwise. As expected, we find that both LEFT VIEWS and IDEALIST are positively correlated with the probability of taking an ENVIRONMENTAL ACTION; the estimated negative marginal effect on STRONG FTR remains significant. The next group of additional predictors for ENVIRONMENTAL ACTION includes three variables. We control for individuals who are optimIST, defined as a dummy to indicate the belief that humanity has a bright future and 0 otherwise. In addition, we include a dummy for HIGH LOCUS OF CONTROL, characterised by an individual's assessment of the degree of free choice and control over their life. Our last variable is a dummy for EXISTENTIALIST, for those who often or sometimes think about meaning and purpose of life in contrast to those who do so rarely or never. We estimate strong positive marginal effects on HIGH LOCUS OF CONTROL and EXISTENTIALIST. The marginal effect on oPTIMIST, however, is indistinguishable from 0 . This regression also confirms the negative significant effect of STRONG FTR on the probability of acting pro-environmentally. In the final column, we introduce controls for the nine language families covering the languages in the sample. Roberts et al. (2015) highlight the significance of controlling for language families in studying the economic effects of linguistic structures. The estimate on STRONG FTR remains robust to the inclusion of these controls.

\footnotetext{
${ }^{16}$ Oster (2016) tests the robustness of treatment parameters from randomized control studies published in reputable economics journals from 2008-2013 and finds that using $R_{\max }=1.3 \widetilde{R}$ reproduces $90 \%$ of randomized results.
} 
Table 3

Individual regressions with baseline and additional controls — Probit marginal effects.

\begin{tabular}{|c|c|c|c|c|c|c|c|}
\hline Control variables & (1) & (2) & (3) & (4) & (5) & (6) & (7) \\
\hline \multirow[t]{2}{*}{ STRONG FTR } & $-0.206 * *$ & $-0.197 * *$ & $-0.089 * * *$ & $-0.086^{* * *}$ & $-0.083^{* *}$ & $-0.082 * *$ & $-0.139 * * *$ \\
\hline & $(0.0927)$ & $(0.089)$ & $(0.027)$ & $(0.029)$ & $(0.032)$ & $(0.034)$ & $(0.030)$ \\
\hline \multirow[t]{2}{*}{ MALE } & & $-0.086^{* * *}$ & $-0.074 * * *$ & $-0.075^{* * *}$ & $-0.075^{* * *}$ & $-0.074 * * *$ & $-0.074 * * *$ \\
\hline & & $(0.014)$ & $(0.007)$ & $(0.007)$ & $(0.008)$ & $(0.007)$ & $(0.007)$ \\
\hline \multirow[t]{2}{*}{ AGE } & & $0.005^{*}$ & $0.007^{* * *}$ & $0.007^{* * *}$ & $0.007 * * *$ & $0.007 * * *$ & $0.007^{* * *}$ \\
\hline & & $(0.003)$ & $(0.001)$ & $(0.001)$ & $(0.001)$ & $(0.001)$ & $(0.001)$ \\
\hline \multirow[t]{2}{*}{ MARRIED } & & 0.008 & $0.024 * * *$ & $0.028 * * *$ & $0.028 * * *$ & $0.029 * * *$ & $0.027^{* * *}$ \\
\hline & & $(0.012)$ & $(0.007)$ & $(0.008)$ & $(0.008)$ & $(0.008)$ & $(0.008)$ \\
\hline \multirow[t]{2}{*}{ NO CHILDREN } & & $0.036^{* * *}$ & $0.016^{* *}$ & $0.014^{*}$ & $0.014^{*}$ & 0.005 & 0.004 \\
\hline & & $(0.011)$ & $(0.007)$ & $(0.007)$ & $(0.007)$ & $(0.008)$ & $(0.008)$ \\
\hline \multirow[t]{2}{*}{ PRIMARY } & & $-0.118 * *$ & $-0.140 * * *$ & $-0.141 * * *$ & $-0.140 * * *$ & $-0.134 * * *$ & $-0.128^{* * *}$ \\
\hline & & $(0.046)$ & $(0.012)$ & $(0.012)$ & $(0.012)$ & $(0.012)$ & $(0.010)$ \\
\hline \multirow[t]{2}{*}{ SECONDARY } & & -0.040 & $-0.059 * * *$ & $-0.058 * * *$ & $-0.057 * * *$ & $-0.052^{* * *}$ & $-0.050^{* * *}$ \\
\hline & & $(0.025)$ & $(0.009)$ & $(0.009)$ & $(0.009)$ & $(0.009)$ & $(0.009)$ \\
\hline \multirow{2}{*}{ EMPLOYED } & & 0.079 & $0.024 * * *$ & $0.021 * * *$ & $0.021 * * *$ & $0.017^{* * *}$ & $0.019^{* * *}$ \\
\hline & & $(0.048)$ & $(0.006)$ & $(0.006)$ & $(0.006)$ & $(0.006)$ & $(0.006)$ \\
\hline \multirow[t]{2}{*}{ TRUST } & & & & $0.031^{* * *}$ & $0.030 * * *$ & $0.035^{* * *}$ & $0.036^{* * *}$ \\
\hline & & & & $(0.010)$ & $(0.010)$ & $(0.010)$ & $(0.010)$ \\
\hline \multirow[t]{2}{*}{ LEFT VIEWS } & & & & & $0.027 * *$ & $0.027 * *$ & $0.031 * * *$ \\
\hline & & & & & $(0.012)$ & $(0.013)$ & $(0.012)$ \\
\hline \multirow[t]{2}{*}{ IDEALIST } & & & & & $0.022 *$ & $0.021 *$ & $0.018^{*}$ \\
\hline & & & & & $(0.012)$ & $(0.012)$ & $(0.011)$ \\
\hline \multirow[t]{2}{*}{ OPTIMIST } & & & & & & 0.000 & 0.005 \\
\hline & & & & & & $(0.012)$ & $(0.010)$ \\
\hline \multirow[t]{2}{*}{ HIGH LOCUS OF CONTROL } & & & & & & $0.049^{* * * *}$ & $0.047^{* * *}$ \\
\hline & & & & & & $(0.013)$ & $(0.012)$ \\
\hline \multirow[t]{2}{*}{ EXISTENTIALIST } & & & & & & $0.093^{* * *}$ & $0.092^{* * *}$ \\
\hline & & & & & & $(0.009)$ & $(0.009)$ \\
\hline Income deciles & No & Yes & Yes & Yes & Yes & Yes & Yes \\
\hline Countries & No & No & Yes & Yes & Yes & Yes & Yes \\
\hline Language families & No & No & No & No & No & No & Yes \\
\hline Pseudo $R^{2}$ & 0.014 & 0.046 & 0.178 & 0.177 & 0.178 & 0.180 & 0.183 \\
\hline $\mathrm{N}$ & 34,461 & 34,461 & 34,461 & 33,087 & 33,087 & 33,087 & 33,083 \\
\hline
\end{tabular}

Note. - Dependent variable is Environmental action. *Denotes significance at 10 percent; **at 5 percent; ***at 1 percent levels.

Next, we ask whether STRONG FTR also affects preference for pro-environmental policies by estimating a version of Eq. (2) where WILLINGNESS TO PAY FOR POLICIES is used as the dependent variable instead. The results of this analysis are reported in Table 4. Indeed, the negative significant effect of STRONG FTR extends to individuals' pro-environmental policy preferences. Estimation results from the most extensive specification reported in column (7) suggest marginal effects of 10.1 percentage points. This implies that the wILLINGNESS TO PAY FOR POLICIES is $24 \%$ lower for speakers of STRONG FTR languages. This is an economically highly significant effect.

The estimated marginal effects on other variables are broadly similar to those obtained from the regressions of ENVIRONMENTAL ACTION with one notable exception: while we established a positive significant correlation between the respondent's age and their probability of taking an ENVIRONMENTAL ACTION, the relationship between age and WILLINGNESS TO PAY FOR POLICIES is negative. As discussed earlier, young people may have larger stakes in environmental quality, and therefore may have stronger demand for pro-environmental policies (Farzin and Bond, 2006). At the same time, older people may feel the environmentally induced health problems more directly, and thus may be more willing to take an ENVIRONMENTAL ACTION; they may also have greater access to time and resources to support environmental initiatives (Farzin and Bond, 2006).

Overall, the findings so far suggest that languages with STRONG FTR lead their speakers to act less pro-environmentally and to extend lower support for pro-environmental policies. In discussing the potential mechanisms of sTRONG FTR above, we mentioned two possibilities: a cultural channel and a linguistic-cognitive channel. To explore the extent to which language is simply serving as a marker for the cultural trait of long term orientation, we control for such proxy generated based on the responses to questions on the degree to which thrift and savings money is an important value to teach children.

Including this measure has no effect on our estimates of STRONG FTR. ${ }^{17}$ This result is very similar to that obtained by Chen (2013), who found that the language future tense effects (in the context of savings behaviour) operate through a channel which is entirely independent of cultural attitudes as captured through the same proxy we use here. There are two ways to interpret this result: either our results support a scenario where FTR operates through the linguistic-cognitive channel; or the proxy we use to capture the respondents' long-term orientation is far from perfect in the context of our study. Strictly distinguishing across various channels underlying our results is a largely infeasible task given the constraints around empirical design and data.

\footnotetext{
${ }^{17}$ We also directly regressed the cultural trait of long term orientation on STRONG FTR and other controls. We obtained insignificant estimates on STRONG FTR throughout. The results of these analyses are available on request.
} 
Table 4

Individual regressions with baseline and additional controls using an alternative dependent variable — Probit marginal effects.

\begin{tabular}{|c|c|c|c|c|c|c|c|}
\hline Control variables & (1) & (2) & (3) & (4) & (5) & (6) & (7) \\
\hline \multirow[t]{2}{*}{ STRONG FTR } & $-0.093 * *$ & $-0.094 * *$ & $-0.097 *$ & $-0.097^{*}$ & $-0.094 *$ & $-0.067 *$ & $-0.101 *$ \\
\hline & $(0.043)$ & $(0.043)$ & $(0.056)$ & $(0.052)$ & $(0.055)$ & $(0.060)$ & $(0.061)$ \\
\hline \multirow[t]{2}{*}{ MALE } & & $-0.020 * * *$ & $-0.027 * * *$ & $-0.025^{* * *}$ & $-0.025^{* * *}$ & $-0.018^{* *}$ & $-0.017 * *$ \\
\hline & & $(0.007)$ & $(0.007)$ & $(0.007)$ & $(0.007)$ & $(0.007)$ & $(0.007)$ \\
\hline \multirow[t]{2}{*}{ AGE } & & -0.002 & $-0.003^{* * *}$ & $-0.004 * * *$ & $-0.004 * * *$ & $-0.004 * * *$ & $-0.004 * * *$ \\
\hline & & $(0.001)$ & $(0.001)$ & $(0.001)$ & $(0.001)$ & $(0.001)$ & $(0.001)$ \\
\hline \multirow[t]{2}{*}{ MARRIED } & & $0.028^{* * *}$ & $0.015^{* *}$ & $0.017 * * *$ & $0.017 * * *$ & $0.014^{*}$ & $0.014 *$ \\
\hline & & $(0.008)$ & $(0.006)$ & $(0.006)$ & $(0.006)$ & $(0.007)$ & $(0.007)$ \\
\hline \multirow[t]{2}{*}{ NO CHILDREN } & & $0.022^{* * *}$ & $0.020 * *$ & $0.017 * *$ & $0.017 * *$ & 0.009 & 0.008 \\
\hline & & $(0.008)$ & $(0.008)$ & $(0.008)$ & $(0.008)$ & $(0.009)$ & $(0.009)$ \\
\hline \multirow[t]{2}{*}{ PRIMARY } & & $-0.048^{*}$ & $-0.083 * * *$ & $-0.082^{* * *}$ & $-0.081 * * *$ & $-0.066 * * *$ & $-0.066^{* * *}$ \\
\hline & & $(0.029)$ & $(0.012)$ & $(0.013)$ & $(0.013)$ & $(0.014)$ & $(0.014)$ \\
\hline \multirow[t]{2}{*}{ SECONDARY } & & $-0.033^{*}$ & $-0.024 * *$ & $-0.021 * *$ & $-0.020 * *$ & -0.011 & -0.011 \\
\hline & & $(0.019)$ & $(0.010)$ & $(0.010)$ & $(0.010)$ & $(0.010)$ & $(0.010)$ \\
\hline \multirow[t]{2}{*}{ EMPLOYED } & & -0.022 & 0.006 & 0.004 & 0.004 & 0.006 & 0.006 \\
\hline & & $(0.019)$ & $(0.007)$ & $(0.007)$ & $(0.007)$ & $(0.007)$ & $(0.007)$ \\
\hline \multirow[t]{2}{*}{ TRUST } & & & & $0.035^{* * *}$ & $0.033^{* * *}$ & $0.028^{* * *}$ & $0.029 * *$ \\
\hline & & & & $(0.011)$ & $(0.011)$ & $(0.012)$ & $(0.012)$ \\
\hline \multirow[t]{2}{*}{ LEFT VIEWS } & & & & & 0.004 & -0.005 & -0.005 \\
\hline & & & & & $(0.010)$ & $(0.011)$ & $(0.011)$ \\
\hline \multirow[t]{2}{*}{ IDEALIST } & & & & & $0.036^{* * *}$ & $0.035^{* * *}$ & $0.035^{* * *}$ \\
\hline & & & & & $(0.009)$ & $(0.009)$ & $(0.009)$ \\
\hline \multirow[t]{2}{*}{ OPTIMIST } & & & & & & $0.023 * *$ & $0.024 * *$ \\
\hline & & & & & & $(0.010)$ & $(0.010)$ \\
\hline \multirow[t]{2}{*}{ HIGH LOCUS OF CONTROL } & & & & & & $0.039 * * *$ & $0.038^{* * *}$ \\
\hline & & & & & & $(0.010)$ & $(0.010)$ \\
\hline \multirow[t]{2}{*}{ EXISTENTIALIST } & & & & & & $0.092^{* * *}$ & $0.092^{* * *}$ \\
\hline & & & & & & $(0.015)$ & $(0.015)$ \\
\hline Income deciles & No & Yes & Yes & Yes & Yes & Yes & Yes \\
\hline Countries & No & No & Yes & Yes & Yes & Yes & Yes \\
\hline Language families & No & No & No & No & No & No & Yes \\
\hline Pseudo $R^{2}$ & 0.002 & 0.009 & 0.044 & 0.045 & 0.046 & 0.049 & 0.050 \\
\hline $\mathrm{N}$ & 38,449 & 38,449 & 38,449 & 38,449 & 37,047 & 30,851 & 30,847 \\
\hline
\end{tabular}

Note. - Dependent variable is WILLINGNESS TO PAY FOR POLICIES. *Denotes significance at 10 percent; **at 5 percent; ***at 1 percent levels.

\subsection{Cross-country results}

\subsubsection{Baseline results}

We established that support for pro-environmental policies is less prevalent among the individuals speakers of STRONG FTR languages. Do we then observe less stringent environmental policies in places where sTRONG FTR language are spoken? This could happen either because the political decisions reflect the preferences of the electorate (Downs, 1957) or if politicians who speak strong-FTR languages have weaker pro-environmental preferences and implement policies consistent with those preferences (Osborne and Slivinski, 1996; Besley and Coate, 1997) or both. The rest of the paper is dedicated to exploring the link between language FTR and environmental policies across countries.

The OLS estimates of the effect of STRONG FTR on our baseline measure of climate change policies, cLIMI, based on Eq. (4) are presented in Table 5. The specification reported in column (1) excludes other controls. Consistent with the descriptive statistics reported in Table 2, the estimates identify a negative relationship between STRONG FTR and CLIMI.

Next, we examine the relationship between STRONG FTR and CLIMI, controlling for economic characteristics of countries (column (2)). The magnitude of the effect of STRONG FTR is smaller, but preserves its significance. As expected, GDP PER CAPITA is positively correlated with CLIMI. Conversely, opENNESS is negatively correlated with CLIMI, possibly reflecting the lack of willingness to commit to stringent environmental policies by exporting countries whose interests may be threatened by such policies. This variable, however, loses its significance once other characteristics of countries are controlled for in columns (3)-(6). Meanwhile, we estimate a significant positive coefficient on MANUFACTURING \%, a variable that potentially captures the pollution-intensity of economies.

We further control for demographic characteristics of countries. The results reported in column (3) demonstrate that the significance of the estimated coefficient on STRONG FTR is robust to inclusion of these controls, although its magnitude is smaller. In the spirit of previous findings on the link between ethnic diversity and public policies (e.g., Easterly and Levine, 1997; Alesina et al., 1999), we show that the share of a country's immigrant population is negatively related to the stringency of its climate change policies. This potentially reflects the difficulties in agreeing on public policies in diverse communities. This effect does not persist, however, once additional controls are included in estimations reported in columns (4)-(6). We also find that the share of a country's elderly population, defined as those aged 65 and above, is positively correlated to the stringency of climate change policies although this effect is not robust to controlling for continents in column (5).

In column (4), we control for institutional characteristics of countries. The estimated coefficient on STRONG FTR is hardly affected. 
Table 5

Baseline cross-country regressions — OLS coefficients.

\begin{tabular}{|c|c|c|c|c|c|c|}
\hline Control variables & $\begin{array}{l}\text { All } \\
(1)\end{array}$ & $\begin{array}{l}\text { All } \\
(2)\end{array}$ & $\begin{array}{l}\text { All } \\
\text { (3) }\end{array}$ & $\begin{array}{l}\text { All } \\
(4)\end{array}$ & $\begin{array}{l}\text { All } \\
\text { (5) }\end{array}$ & $\begin{array}{l}\text { No outliers } \\
\text { (6) }\end{array}$ \\
\hline STRONG FTR & $\begin{array}{l}-0.146^{* *} \\
(0.068)\end{array}$ & $\begin{array}{l}-0.095^{* *} \\
(0.038)\end{array}$ & $\begin{array}{l}-0.078^{* *} \\
(0.034)\end{array}$ & $\begin{array}{l}-0.081^{* *} \\
(0.032)\end{array}$ & $\begin{array}{l}-0.061 * \\
(0.033)\end{array}$ & $\begin{array}{l}-0.097^{* * *} \\
(0.035)\end{array}$ \\
\hline GDP PER CAPITA & & $\begin{array}{l}0.133^{* * *} \\
(0.025)\end{array}$ & $\begin{array}{l}0.109^{* * *} \\
(0.031)\end{array}$ & $\begin{array}{l}0.077^{* * * *} \\
(0.029)\end{array}$ & $\begin{array}{l}0.087^{* * *} \\
(0.029)\end{array}$ & $\begin{array}{l}0.068^{* *} \\
(0.027)\end{array}$ \\
\hline OPENNESS & & $\begin{array}{l}-0.086 * \\
(0.043)\end{array}$ & $\begin{array}{l}-0.057 \\
(0.059)\end{array}$ & $\begin{array}{l}-0.005 \\
(0.058)\end{array}$ & $\begin{array}{r}-0.045 \\
(0.070)\end{array}$ & $\begin{array}{l}-0.046 \\
(0.066)\end{array}$ \\
\hline MANUFACTURING $\%$ & & $\begin{array}{l}0.012^{* * *} \\
(0.004)\end{array}$ & $\begin{array}{l}0.009 * * \\
(0.004)\end{array}$ & $\begin{array}{l}0.006^{*} \\
(0.004)\end{array}$ & $\begin{array}{l}0.008^{* *} \\
(0.004)\end{array}$ & $\begin{array}{l}0.009 * * \\
(0.004)\end{array}$ \\
\hline POPULATION SIZE & & & $\begin{array}{l}0.003 \\
(0.016)\end{array}$ & $\begin{array}{l}0.003 \\
(0.017)\end{array}$ & $\begin{array}{r}-0.001 \\
(0.020)\end{array}$ & $\begin{array}{l}0.001 \\
(0.020)\end{array}$ \\
\hline IMMIGRANT \% & & & $\begin{array}{l}-0.005^{* *} \\
(0.002)\end{array}$ & $\begin{array}{r}-0.003 \\
(0.002)\end{array}$ & $\begin{array}{r}-0.002 \\
(0.002)\end{array}$ & $\begin{array}{r}-0.002 \\
(0.002)\end{array}$ \\
\hline POPULATION AGE $65+\%$ & & & $\begin{array}{l}0.013^{* * *} \\
(0.005)\end{array}$ & $\begin{array}{l}0.009 * * \\
(0.004)\end{array}$ & $\begin{array}{l}0.003 \\
(0.006)\end{array}$ & $\begin{array}{l}0.003 \\
(0.006)\end{array}$ \\
\hline DEMOCRACY & & & & $\begin{array}{l}0.182^{* * *} \\
(0.048)\end{array}$ & $\begin{array}{l}0.210^{* * *} \\
(0.053)\end{array}$ & $\begin{array}{l}0.218^{* * *} \\
(0.052)\end{array}$ \\
\hline LEFT GOVERNMENT & & & & $\begin{array}{l}0.004 \\
(0.044)\end{array}$ & $\begin{array}{l}0.020 \\
(0.048)\end{array}$ & $\begin{array}{l}0.014 \\
(0.049)\end{array}$ \\
\hline Constant & $\begin{array}{l}0.517^{* * *} \\
(0.062)\end{array}$ & $\begin{array}{l}-0.917^{* * *} \\
(0.218)\end{array}$ & $\begin{array}{l}-0.837 * * \\
(0.384)\end{array}$ & $\begin{array}{c}-0.633^{*} \\
(0.375)\end{array}$ & $\begin{array}{r}-0.575 \\
(0.395)\end{array}$ & $\begin{array}{r}-0.413 \\
(0.382)\end{array}$ \\
\hline Continents & No & No & No & No & Yes & Yes \\
\hline$R^{2}$ & 0.075 & 0.530 & 0.643 & 0.724 & 0.749 & 0.755 \\
\hline $\mathrm{N}$ & 70 & 68 & 68 & 68 & 68 & 64 \\
\hline
\end{tabular}

Note.- Dependent variable is cLImI. Columns (1)-(5) report the results based on the full sample. Column (6) reports the results in a sample where outliers are removed; these are identified by predicting DFbetas for STRONG FTR from the full sample regression and then dropping those observations for which $\mid$ DFbeta $\mid>2 / \sqrt{N}$. Columns $(5)$ and (6) include continent dummies. *Denotes significance at 10 percent; **at 5 percent; ***at 1 percent levels.

We find that the stringency of climate change policies is higher in democracies, consistent with other findings in the literature (e.g., Murdoch and Sandler, 1997; Farzin and Bond, 2006). The estimated coefficient on LEFT GOVERnMENT, while positive, is insignificant.

Finally, in column (5) we control for economic, demographic and institutional characteristics of countries, and also include dummies for continents. The significant negative effect of STRONG FTR on CLIMI persists: we estimate that CLIMI is 0.06 points lower in countries with a STRONG FTR, relative to a WEAK FTR majority language. This is equivalent to a 15\% decrease in CLIMI, implying, for example, that if Greece were to switch from a strong- to a weak-FTR language, the stringency of their climate change policies would be at the level of those observed in Sweden (our estimates are reasonably precise relative to the difference in actual stringency of climate change policies between the two countries).

In column (6), we evaluate the sensitivity of this finding to the potential presence of influential observations calculated based on DFbetas for sTRONG FTR from baseline regression in column (5). We drop those observations for which $|\mathrm{DFbeta}|>2 / \sqrt{N}$ (Belsley et al., 1980). The estimated coefficient on STRONG FTR is more significant in this sample, both in statistical and economic terms.

\subsubsection{Robustness checks}

We have established a statistically significant negative relationship between sTRONG FTR and CLIMI. An important question is whether language simply acts as a marker of unobserved characteristics, or whether language itself has a direct causal effect (Mavisakalyan and Weber, 2017). In Table 6, we explore this issue by including several additional controls (to allow for comparisons, column (1) repeats the estimate from baseline specification in column (5) of Table 5).

First, we run a placebo regression with a different linguistic feature which is irrelevant to the outcome of our study, as an additional control (e.g., Mavisakalyan, 2015). The feature we control for is LANGUAGE GENDER, a measure of grammatical gender intensity in a language that comes from Gay et al. (2017) (the study provides the details on how this measure is constructed). Reassuringly, the results presented in column (2) show that this linguistic feature is unrelated to cuIm, while the estimated significant negative effect on STRONG FTR persists.

Existing attempts to isolate the economic effect of linguistic measures have considered the relevance of historic origins of countries. These may potentially confound the estimated effect of STRONG FTR, as they may influence linguistic and cultural evolution, while also being relevant for policy outcomes either through affecting these directly or through other channels. To mitigate the effect of associated bias, we introduce controls for the nine language families covering the languages in the sample. The estimate on strong FTR is robust to the inclusion of these controls (which in turn are jointly significant) (column 3).

Another possibility to consider is that linguistic features of countries are spatially correlated, i.e. that there is a concentration of linguistic features in certain areas. The estimated effect on STRONG FTR may then be due to correlated geographic and climatic factors. To address this concern, our baseline list of controls includes continent fixed effects. In column (4) we additionally control for countries' LANDLOCKED status, their LATITUDE and the total rents they derive from natural resources as a share of GDP-features that have been linked to countries' economic development (e.g., Hall and Jones, 1999); they have also been used in previous attempts to isolate 
Table 6

Cross-country regressions with additional controls- OLS coefficients.

\begin{tabular}{|c|c|c|c|c|c|}
\hline Control variables & (1) & (2) & (3) & (4) & (5) \\
\hline \multirow[t]{2}{*}{ STRONG FTR } & $-0.061^{*}$ & $-0.076^{* *}$ & $-0.091^{*}$ & $-0.096^{* *}$ & $-0.113^{* * *}$ \\
\hline & $(0.033)$ & $(0.033)$ & $(0.048)$ & $(0.045)$ & $(0.056)$ \\
\hline \multirow[t]{2}{*}{ LANGUAGE GENDER } & & 0.022 & 0.033 & 0.036 & 0.031 \\
\hline & & $(0.014)$ & $(0.026)$ & $(0.025)$ & $(0.026)$ \\
\hline \multirow[t]{2}{*}{ LANDLOCKED } & & & & -0.007 & 0.007 \\
\hline & & & & $(0.051)$ & $(0.060)$ \\
\hline \multirow[t]{2}{*}{ LATITUDE } & & & & -0.017 & -0.004 \\
\hline & & & & $(0.196)$ & $(0.217)$ \\
\hline \multirow[t]{2}{*}{ RESOURCES RENTS \% } & & & & $-0.005 * * *$ & $-0.004 * *$ \\
\hline & & & & $(0.002)$ & $(0.002)$ \\
\hline \multirow[t]{2}{*}{ COMMON LAW } & & & & & 0.052 \\
\hline & & & & & $(0.118)$ \\
\hline \multirow[t]{2}{*}{ FRENCH CIVIL LAW } & & & & & 0.060 \\
\hline & & & & & $(0.064)$ \\
\hline \multirow[t]{2}{*}{ Constant } & -0.575 & -0.654 & -0.684 & -0.408 & -0.360 \\
\hline & $(0.395)$ & $(0.417)$ & $(0.419)$ & $(0.400)$ & $(0.511)$ \\
\hline Language families & No & No & Yes & Yes & Yes \\
\hline Baseline controls & Yes & Yes & Yes & Yes & Yes \\
\hline$R^{2}$ & 0.749 & 0.760 & 0.813 & 0.846 & 0.851 \\
\hline $\mathrm{N}$ & 68 & 68 & 65 & 64 & 64 \\
\hline
\end{tabular}

Note. - Dependent variable is CLIMI. *Denotes significance at 10 percent; **at 5 percent; ***at 1 percent levels.

the effect of linguistic measures on various outcomes (e.g., Mavisakalyan, 2015). Our estimates on LANDLOCKED and LATITUDE are insignificant, while RESOURCES RENTS \% is negatively significantly correlated with CLIMI. The significant negative effect of STRONG FTR is robust to this addition to the list of controls.

Finally, we control for the institutional relatedness of countries in the sample by introducing controls for the origins of their legal systems. These have been included in other attempts to mitigate the effect of unobserved heterogeneity in studying the effect of linguistic measures on economic outcomes (e.g., Chen et al., 2015; Roberts et al., 2015). Furthermore, there is evidence to suggest that they might affect climate change policies (Fredriksson and Wollscheid, 2015). Most sources distinguish between two main secular legal traditions: common law and civil law, and several subtraditions-French, German, Socialist, and Scandinavian-within civil law (Porta et al., 1998; La Porta et al., 2008). French civil law and common law are the most common internationally, and dummies for these legal systems are included in the regressions reported in column (5). The estimated coefficients on these dummies are insignificant, while the effect of STRONG FTR is significant and sizeable. ${ }^{18}$

As another robustness check of the cross-country results we explore whether the results are sensitive to how STRONG FTR is assigned. In the baseline models, STRONG FTR is assigned to a country's majority language. This potentially conceals the differences across linguistically distinct groups in diverse societies. To address this issue, we introduce a refinement: we replace the STRONG FTR dummy with a continuous variable, STRONG FTR \%, measuring the total population share speaking a sTRONG FTR language. Data on FTR for some of the minority languages is missing. Similar to the approach in Mavisakalyan (2015), we restrict the sample to countries where information on language FTR is available for at least $80 \%$ of the population, and additionally control for the share of the population with unknown language FTR.

The results are reported in Table 7. For ease of comparisons, column (1) reports the results with our baseline measure of sTRONG FTR (this corresponds to the estimates from the model with the comprehensive list of controls presented in column (5) of Table 6). The results of the regression of CLIMI on our alternative measure of language FTR and comprehensive list of controls are presented in column (2). The estimated coefficient on STRONG FTR \% is negative and significant, albeit small in magnitude, while that on UNKNOwN FTR $\%$ is insignificant.

\subsubsection{Addressing endogeneity}

The above shows that the effect of STRONG FTR persists, even when proxies for unobserved heterogeneity are included. Still, unobserved heterogeneity can never be completely excluded. The standard approach to address the problem of omitted variable bias is to use an instrumental variable. This is what we pursue here: building on the findings by Galor et al. (2016); Galor and Özak (2016), we exploit CROP YEILD as an instrument for STRONG FTR in estimating its effect on CLIMI.

The results of this exercise are summarised in Table 8. To allow for comparisons, the corresponding OLS estimates are reported in columns (1) and (3) (these are identical to those reported in column (5) of Table 5 and column (5) of Table 6). The estimates from the

\footnotetext{
18 Davis and Williamson (2016) propose an Interdependent Institutions Hypothesis, according to which there is an interaction between formal and informal institutions and the effect of culture (i.e. informal institutions) may depend on the formal institutional context. Certain legal and political frameworks are more permeable for cultural influences, or may even amplify these, e.g. "democracy and the common law tradition magnify the [cultural] influence of individualism" (Davis and Williamson, 2016, p. 1056). We explored whether this possibility holds in our context by including interaction terms of STRONG FTR and DEMOCRACY and STRONG FTR and legal origin dummies in estimations. These were insignificant throughout.
} 
Table 7

Cross-country regressions using an alternative independent variable - OLS coefficients.

\begin{tabular}{lll}
\hline Control variables & $(1)$ & $(2)$ \\
\hline STRONG FTR & $-0.113^{* *}$ & \\
STRONG FTR \% & $(0.056)$ & $-0.001^{*}$ \\
& & $(0.001)$ \\
UNKNOWN FTR \% & & 0.006 \\
& & $(0.004)$ \\
Constant & -0.360 & -0.303 \\
& $(0.511)$ & $(0.669)$ \\
Baseline controls & Yes & Yes \\
Additional controls & Yes & Yes \\
$R^{2}$ & 0.851 & 0.853 \\
$\mathrm{~N}$ & 64 & 58 \\
\hline
\end{tabular}

Note.-Dependent variable is CLIMI. STRONG FTR \% is the share of population speaking a STRONG FTR language. UNKNOWN FTR \% is the share of population speaking a language with missing FTR data. The regression in column (2) is restricted to countries with UNKNOWN FTR $\% \leq 20$. *Denotes significance at 10 percent; **at 5 percent; ***at 1 percent levels.

Table 8

Cross-country 2SLS regressions.

\begin{tabular}{|c|c|c|c|c|}
\hline Control variables & $\begin{array}{l}\text { OLS } \\
(1)\end{array}$ & $\begin{array}{l}\text { 2SLS } \\
\text { (2) }\end{array}$ & $\begin{array}{l}\text { OLS } \\
(3)\end{array}$ & $\begin{array}{l}\text { 2SLS } \\
\text { (4) }\end{array}$ \\
\hline STRONG FTR & $\begin{array}{l}-0.061 * \\
(0.033)\end{array}$ & $\begin{array}{c}-0.188^{*} \\
(0.108)\end{array}$ & $\begin{array}{l}-0.113^{* *} \\
(0.056)\end{array}$ & $\begin{array}{l}-0.244^{* * *} \\
(0.088)\end{array}$ \\
\hline GDP PER CAPITA & $\begin{array}{l}0.087^{* * *} \\
(0.029)\end{array}$ & $\begin{array}{l}0.069 * * \\
(0.028)\end{array}$ & $\begin{array}{l}0.119 * * * \\
(0.042)\end{array}$ & $\begin{array}{l}0.087 * * \\
(0.036)\end{array}$ \\
\hline OPENNESS & $\begin{array}{l}-0.045 \\
(0.070)\end{array}$ & $\begin{array}{l}-0.030 \\
(0.059)\end{array}$ & $\begin{array}{l}-0.028 \\
(0.078)\end{array}$ & $\begin{array}{r}-0.058 \\
(0.062)\end{array}$ \\
\hline MANUFACTURING \% & $\begin{array}{l}0.008^{* *} \\
(0.004)\end{array}$ & $\begin{array}{l}0.007 \\
(0.004)\end{array}$ & $\begin{array}{l}0.005 \\
(0.006)\end{array}$ & $\begin{array}{l}0.007 \\
(0.005)\end{array}$ \\
\hline POPULATION SIZE & $\begin{array}{r}-0.001 \\
(0.020)\end{array}$ & $\begin{array}{l}0.010 \\
(0.020)\end{array}$ & $\begin{array}{r}-0.013 \\
(0.022)\end{array}$ & $\begin{array}{r}-0.016 \\
(0.017)\end{array}$ \\
\hline IMMIGRANT \% & $\begin{array}{r}-0.002 \\
(0.002)\end{array}$ & $\begin{array}{r}-0.002 \\
(0.002)\end{array}$ & $\begin{array}{r}-0.002 \\
(0.003)\end{array}$ & $\begin{array}{r}-0.004 \\
(0.003)\end{array}$ \\
\hline POPULATION AGE $65+\%$ & $\begin{array}{l}0.003 \\
(0.006)\end{array}$ & $\begin{array}{l}0.003 \\
(0.005)\end{array}$ & $\begin{array}{l}-0.005 \\
(0.008)\end{array}$ & $\begin{array}{l}-0.002 \\
(0.007)\end{array}$ \\
\hline DEMOCRACY & $\begin{array}{l}0.210 * * * \\
(0.053)\end{array}$ & $\begin{array}{l}0.199 * * * \\
(0.048)\end{array}$ & $\begin{array}{l}0.233^{* * *} \\
(0.055)\end{array}$ & $\begin{array}{l}0.223^{* * *} \\
(0.041)\end{array}$ \\
\hline LEFT GOVERNMENT & $\begin{array}{l}0.020 \\
(0.048)\end{array}$ & $\begin{array}{l}0.006 \\
(0.047)\end{array}$ & $\begin{array}{l}0.037 \\
(0.062)\end{array}$ & $\begin{array}{l}0.021 \\
(0.048)\end{array}$ \\
\hline LANGUAGE GENDER & & & $\begin{array}{l}0.031 \\
(0.026)\end{array}$ & $\begin{array}{l}0.032 \\
(0.021)\end{array}$ \\
\hline LANDLOCKED & & & $\begin{array}{l}0.007 \\
(0.060)\end{array}$ & $\begin{array}{l}0.014 \\
(0.050)\end{array}$ \\
\hline LATITUDE & & & $\begin{array}{l}-0.004 \\
(0.217)\end{array}$ & $\begin{array}{l}-0.051 \\
(0.155)\end{array}$ \\
\hline RESOURCES RENTS \% & & & $\begin{array}{l}-0.004 * * \\
(0.002)\end{array}$ & $\begin{array}{l}-0.004^{* * *} \\
(0.001)\end{array}$ \\
\hline COMMON LAW & & & $\begin{array}{l}0.052 \\
(0.118)\end{array}$ & $\begin{array}{l}0.151 \\
(0.098)\end{array}$ \\
\hline FRENCH CIVIL LAW & & & $\begin{array}{l}0.060 \\
(0.064)\end{array}$ & $\begin{array}{l}0.097^{*} \\
(0.050)\end{array}$ \\
\hline Constant & $\begin{array}{r}-0.575 \\
(0.395)\end{array}$ & $\begin{array}{r}-0.512 \\
(0.344)\end{array}$ & $\begin{array}{r}-0.360 \\
(0.511)\end{array}$ & $\begin{array}{r}-0.249 \\
(0.394)\end{array}$ \\
\hline Continents & Yes & Yes & Yes & Yes \\
\hline Language families & No & No & Yes & Yes \\
\hline$R^{2}$ & 0.749 & 0.699 & 0.851 & 0.830 \\
\hline N & 68 & 68 & 64 & 64 \\
\hline
\end{tabular}

Note. - Dependent variable is cLimI. *Denotes significance at 10 percent; **at 5 percent; **at 1 percent levels. $\dagger$ The $H_{o}$ is that the first stage regression is weakly identified. 
Table 9

Test of omitted variable bias - Cross-country results.

\begin{tabular}{|c|c|c|c|c|}
\hline Specification & $\delta_{R \max }=0.90$ & {$\left[\tilde{\beta}, \beta_{\left(R_{\max }=0.90, \delta=1\right)}^{*}\right]$} & $\delta_{R \max }=\min \{1.3 \widetilde{R}, 1\}$ & {$\left[\widetilde{\beta}, \beta_{\left(R_{\max }=\min \{1.3 \widetilde{R}, 1\}, \delta=1\right)}^{*}\right.$} \\
\hline & & $(2)$ & (3) & $(4)$ \\
\hline BASELINE CONTROL & 2.689 & {$[-0.060,-0.040]$} & 1.728 & {$[-0.060,-0.027]$} \\
\hline COMPREHENSIVE CONTROLS & 3.119 & {$[-0.112,-2.106]$} & 1.300 & {$[-0.111,-1.674]$} \\
\hline
\end{tabular}

Note. $-\delta$ indicates the value of proportional selection of unobservables to observables assuming the maximum value of theoretical $R^{2}$ is $R_{\max }$. The coefficient bounds are calculated assuming the unobservables are as important as the observables in explaining the outcome variable (i.e. $\delta=1$ ).

2nd stage of the 2SLS models with baseline as well as with comprehensive lists of controls confirm the negative significant effect of STRONG FTR. Moreover, the magnitudes of the estimated effects are larger. In defence of our identification strategy, the statistics for the weak identification test (Kleibergen and Paap, $2006 \mathrm{~F}$ statistics) provides no evidence that the instrument we use is weak or irrelevant.

As an additional approach to address the potential problem of endogeneity of sTRONG FTR, we apply the partial identification approach proposed by Oster (2016). The results of this test are presented in Table 9.

In columns (2) and (4) we report the coefficient bounds $\left[\widetilde{\beta}, \beta^{*}\right]$ for models with baseline and comprehensive lists of controls (reported in column (5) of Table 5 and column (5) of Table 6 respectively). The first bound $\widetilde{\beta}$ comes from the specifications controlling for all baseline/comprehensive observables. The second bound $\beta^{*}$ is evaluated using Eq. (6) by setting $\delta=1$ and applying two assumptions on the value of $R_{\max }$. First, we assume $R_{\max }=0.90$. i.e. that the measurement error in CLIMI accounts for $10 \%$ of the variation therein (column (2)). Second, we apply the rule of thumb proposed by Oster (2016) in setting $R_{\max }$ equal to the minimum of one or to the R-squared from the regression controlling for all observables multiplied by a factor of 1.3 (column (4)). Furthermore, in columns (1) and (3) we report the corresponding estimates of $\delta$ that would be needed to explain away the entire causal effect of sTRONG FTR On CLIMI.

None of the estimated bounds include 0 . This suggests that at least part of the estimated effect on sTRONG FTR is likely to be causal. Moreover, in all cases $\delta>1$, i.e. the unobservables would have to be more important than the observables in explaining cLIMI. This provides further assurance that the results are robust to omitted variables.

\subsubsection{Implications for international environmental cooperation}

Our baseline dependent variable, CLIMI, measures climate change mitigation policies adopted by countries in four key policy areas including (i) international cooperation; (ii) domestic climate framework; (iii) significant sectoral fiscal or regulatory measures or targets; and (iv) additional cross-sectoral fiscal or regulatory measures (Steves et al., 2011). While we have established that sTRONG FTR affects CLIMI, so far the analysis does not tell us whether and to what extent this effect applies to individual policy areas.

Here we focus on the link between STRONG FTR and global environmental cooperation, as captured by GLOBAL, given its particularly significant role in climate change mitigation efforts. Moreover, future tense might influence international cooperation through an additional channel. ${ }^{19}$

Avoiding global warming and maintaining atmospheric temperatures at current levels is a public good. As is well-known, public goods lead to social dilemmas. Individual actors have an interest both in the goods production and in avoiding the costs of its production. As public goods are non-excludable, narrow self-interest dictates to free-ride. If most defect from shouldering the burden of the goods production, it won't be produced and everyone is worse off. Applied to our case, every nation has an interest in both maintaining current temperature levels and also in avoiding the costs of doing so; but if most nations act in their narrow self-interest, catastrophic climate change seems inevitable.

Empirically, the actual rate of cooperation in such situations is much higher than a game-theoretic model based on narrow selfinterest predicts. There are several psychological factors which increase actors' willingness to cooperate. The two most important ones are social value orientation (Messick and McClintock, 1968; Van Lange, 1999) and trust (Dawes, 1980; Yamagishi, 2011). However, there is an additional factor which has recently received attention: orientation towards the future: "A [...] trait relevant to cooperation in social dilemmas is the consideration of future consequences ( $\mathrm{CFC}$ ), defined as 'the extent to which people consider the potential distant outcomes of their current behaviours and the extent to which they are influenced by these potential outcomes' (Strathman et al., 1994; Joireman et al., 2012, p. 743)." (Van Lange et al., 2014, p. 64); see also (Parks, 2015). Further, theoretical models suggest that in repeated prisoner dilemma games (i.e. situations that reflect the incentive structure of public goods dilemmas), anticipatory strategies that predict the future rate of other players' cooperative behaviour are more successful and realistic than strategies based on subjective utility calculations and backward looking learning mechanisms (Lalev and Grinberg, 2006). So, both empirical and theoretical considerations suggest that future orientation increases cooperation.

As the absence of future tense is associated with increased future orientation, we expect that countries with weak-FTR languages, and thus higher orientation towards the future, should be more willing to cooperate on climate change and adopt policy measure that are conducive to combating climate change, even if these policies hurt their short-term interest. This is indeed what we find. In the parsimonious specification reported in column (1) of Table 10 we report a highly significant negative coefficient on STRONG FTR. This

\footnotetext{
${ }^{19}$ We are thankful to an anonymous referee for raising this point.
} 
Table 10

Cross country regressions using an alternative dependent variable.

\begin{tabular}{|c|c|c|c|}
\hline \multirow[t]{2}{*}{ Control variables } & \multicolumn{2}{|l|}{ OLS } & \multirow{2}{*}{$\begin{array}{l}\text { 2SLS } \\
\text { (3) }\end{array}$} \\
\hline & (1) & (2) & \\
\hline STRONG FTR & $\begin{array}{l}-0.628^{* * *} \\
(0.176)\end{array}$ & $\begin{array}{l}-0.679^{* * *} \\
(0.172)\end{array}$ & $\begin{array}{c}-0.736^{*} \\
(0.418)\end{array}$ \\
\hline GDP PER CAPITA & & $\begin{array}{l}0.058 \\
(0.122)\end{array}$ & $\begin{array}{l}0.053 \\
(0.119)\end{array}$ \\
\hline OPENNESS & & $\begin{array}{l}0.087 \\
(0.206)\end{array}$ & $\begin{array}{l}0.091 \\
(0.189)\end{array}$ \\
\hline MANUFACTURING \% & & $\begin{array}{l}0.004 \\
(0.016)\end{array}$ & $\begin{array}{l}0.003 \\
(0.016)\end{array}$ \\
\hline POPULATION SIZE & & $\begin{array}{l}0.174 * * * \\
(0.042)\end{array}$ & $\begin{array}{l}0.176^{* * *} \\
(0.041)\end{array}$ \\
\hline IMMIGRANT \% & & $\begin{array}{l}0.002 \\
(0.011)\end{array}$ & $\begin{array}{l}0.002 \\
(0.011)\end{array}$ \\
\hline POPULATION AGE $65+\%$ & & $\begin{array}{l}0.038 * \\
(0.019)\end{array}$ & $\begin{array}{l}0.038^{* *} \\
(0.018)\end{array}$ \\
\hline DEMOCRACY & & $\begin{array}{l}0.117 \\
(0.163)\end{array}$ & $\begin{array}{l}0.110 \\
(0.158)\end{array}$ \\
\hline LEFT GOVERNMENT & & $\begin{array}{l}-0.071 \\
(0.152)\end{array}$ & $\begin{array}{r}-0.076 \\
(0.140)\end{array}$ \\
\hline Constant & $\begin{array}{l}0.704 * * * \\
(0.161)\end{array}$ & $\begin{array}{l}-3.007^{* *} \\
(1.157)\end{array}$ & $\begin{array}{l}-2.951^{* * *} \\
(1.140)\end{array}$ \\
\hline Continents & No & Yes & Yes \\
\hline$R^{2}$ & 0.135 & 0.468 & 0.467 \\
\hline $\mathrm{N}$ & 93 & 85 & 85 \\
\hline$\delta_{R_{\max }=\min \{1.3 \widetilde{R}, 1\}}$ & & 2.742 & \\
\hline Kleibergen and Paap (2006) F statistics $\dagger$ & & & 10.798 \\
\hline
\end{tabular}

Note.-Dependent variable is GLoBal. *Denotes significance at 10 percent; **at 5 percent; ***at 1 percent levels. $\delta$ indicates the value of proportional selection of unobservables to observables assuming the maximum value of theoretical $R^{2}$ is $R_{\max }$. The coefficient bounds are calculated assuming the unobservables are as important as the observables in explaining the outcome variable (i.e. $\delta=1$ ). $\dagger$ The $H_{o}$ is that the first stage equation is weakly identified.

result is remarkably robust to including the entire list of baseline controls in column (2). We also address the endogeneity of sTRONG FTR using CROP YEILD as an instrument. Column (3) reports the results of the second stage regression where the estimated coefficient on STRONG FTR remains robust and significant. Applying the partial identification approach proposed by Oster (2016) yields similar results: we find $\delta>1$, i.e. the unobservables would have to be more important than the observables in explaining GLOBAL.

\section{Conclusion}

Our findings support the idea that future tense marking in language affects speakers' future-oriented behaviour. The evidence presented here indicates that this effect includes pro-environmental action: at the individual level, speakers of weak-FTR languages are more willing to engage in costly pro-environmental actions and to support pro-environmental policies; at the country level, nations with weak-FTR language, i.e. that speak about the future as it were present, have more stringent environmental policies.

We have proposed that there are two possible channels for this influence: a cultural channel via speakers' long-term orientation or a linguistic-cognitive channel via speakers' perception of temporal distance. Both affect agents' intertemporal preference structure such that weak-FTR speakers discount future costs and rewards less than do strong-FTR speakers. Individuals that speak about the future in the present tense care more about it. There is reason to believe that future tense marking does indeed causally influence proenvironmental behaviour and policies. First, we show that the effect persists after controlling for geographic and historical relatedness of languages. Second, applying full and partial identification approaches also yields support for a causal effect.

Our results have potential implications for policy making. They show that pro-environmental governments or lobby groups face particular obstacles in countries with strong-FTR languages. It seems unrealistic to expect countries to engage in linguistic reforms with the aim of turning strong-FTR languages into weak-FTR ones, at least in the short term. But there are other possible consequences. One may, for instance, conclude that environmental campaigns in strong-FTR countries should especially aim to counterbalance the effect of FTR and portray the risks of climate change as real and urgent. Further, international organisations may decide that investing in environmental projects in weak-FTR countries (that are otherwise equal) has a better payoff, as their citizens will be more receptive for environmental concerns.

\section{References}

Alesina, A., Baqir, R., Easterly, W., 1999. Public goods and ethnic divisions. Q. J. Econ. 114 (4), 1243. http://dx.doi.org/10.1162/003355399556269. Alesina, A., Devleeschauwer, A., Easterly, W., Kurlat, S., Wacziarg, R., 2003. Fractionalization. J. Econ. Growth 8 (2), 155-194. http://dx.doi.org/10.1023/ A:1024471506938. 
Altonji, J.G., Elder, T.E., Taber, C.R., 2005. Selection on observed and unobserved variables: assessing the effectiveness of catholic schools. J. Pol. Econ. 113 (1), $151-184$

Ang, J.B., Fredriksson, P.G., 2017. Statehood experience, legal traditions, and climate change policies. Econ. Inq. 55 (3), 1511-1537. http://dx.doi.org/10.1111/ecin. 12441.

Bechtel, M.M., Genovese, F., Scheve, K., 2016. Interests, Norms, and Mass Support for International Climate Policy. Working Paper.

Beck, T., Clarke, G., Groff, A., Keefer, P., Walsh, P., 2001. New tools in comparative political economy: the database of political institutions. World Bank Econ. Rev. 15 (1), 165-176.

Belsley, D.A., Kuh, E., Welsch, R.E., 1980. Regression Diagnostics. Wiley and Sons, New York.

Besley, T., Coate, S., 1997. An economic model of representative democracy. Q. J. Econ. 112 (1), 85. http://dx.doi.org/10.1162/003355397555136.

Bhalotra, S., Clarke, D., Gomes, J., Venkataramani, A., 2015. Maternal mortality and female life expectancy: the importance of gender inequality.

Blocker, T.J., Eckberg, D.L., 1997. Gender and environmentalism: results from the 1993 general social survey. Soc. Sci. Q. 78 (4), 841-858.

Boroditsky, L., Schmidt, L.A., Phillips, W., 2003. Sex, Syntax, and Semantics. In: Gentner, D., Goldin-Meadow, S. (Eds.), Language in Mind: Advances in the study of language and thought. MIT press, Cambridge, pp. 61-79.

Bybee, J.L., Perkins, R.D., Pagliuca, W., 1994. The Evolution of Grammar: Tense, Aspect, and Modality in the Languages of the World. University of Chicago Press, Chicago.

Casasanto, D., 2015. Linguistic Relativity. In: Riemer, N. (Ed.), Routledge handbook of semantics. Routledge, New York, pp. $158-174$.

Chen, M.K., 2013. The effect of language on economic behavior: evidence from savings rates, health behaviors, and retirement assets. Am. Econ. Rev. 103 (2), 690-731. http://dx.doi.org/10.1257/aer.103.2.690.

Chen, S., Cronqvist, H., Ni, S., Zhang, F., 2015. Languages and Corporate Cash Holdings: International Evidence. Technical Report. China Europe International Business School.

Cole, M.A., Elliott, R.J.R., Fredriksson, P.G., 2006. Endogenous pollution havens: does FDI influence environmental regulations? Scandinavian J. Econ. 108 (1), 157-178. http://dx.doi.org/10.1111/j.1467-9442.2006.00439.x.

Congleton, R.D., 1992. Political institutions and pollution control. Rev. Econ. Stat. 74 (3), $412-421$.

Cyffer, N., Ebermann, E., Ziegelmeyer, G., 2009. Negation Patterns in West African Languages and Beyond. John Benjamins Publishing, Amsterdam.

Dahl, Ö., 1985. Tense and Aspect Systems. Basil Blackwell, Oxford.

Dahl, Ö., 2000. The Grammar of Future Time Reference in European Languages. In: Dahl, Ö. (Ed.), Tense and Aspect in the Languages of Europe. Mouton de Gruyter, Berlin.

Dahl, Ö., Dienes, D.K., 1984. Selected working papers from the tense-Mood-Aspect project. Institute of Linguistics, University of Stockholm.

Damania, R., Fredriksson, P.G., 2003. Trade policy reform, endogenous lobby group formation, and environmental policy. J. Econ. Behav. Org. 52 (1), 47-69. http:// dx.doi.org/10.1016/S0167-2681(02)00194-4.

Damania, R., Fredriksson, P.G., List, J.A., 2003. Trade liberalization, corruption, and environmental policy formation: theory and evidence. J. Environ. Econ. Manage. 46 (3), 490-512. http://dx.doi.org/10.1016/S0095-0696(03)00025-1.

Davis, L., Reynolds, M., 2016. Gendered language and the educational gender gap. SSRN.

Davis, L.S., Abdurazokzoda, F., 2016. Language, culture and institutions: evidence from a new linguistic dataset. J. Comp. Econ. 44 (3), 541-561. http://dx.doi.org/10. 1016/j.jce.2015.10.015.

Davis, L.S., Williamson, C.R., 2016. Culture and the regulation of entry. J. Comp. Econ. 44 (4), 1055-1083. http://dx.doi.org/10.1016/j.jce.2016.09.007.

Dawes, R.M., 1980. Social dilemmas. Ann. Rev. Psychol. 31 (1), 169-193.

Downs, A., 1957. An Economic Theory of Democracy. Harper and Row, New York.

Easterly, W., Levine, R., 1997. Africa’s growth tragedy: policies and ethnic divisions*. Q. J. Econ. 112 (4), 1203. http://dx.doi.org/10.1162/003355300555466.

Esty, D.C., Levy, M., Srebotnjak, T., De Sherbinin, A., 2005. Environmental sustainability index: benchmarking national environmental stewardship. Technical Report. Yale Center for Environmental Law \& Policy.

Farzin, Y.H., Bond, C.A., 2006. Democracy and environmental quality. J. Dev. Econ. 81 (1), 213-235. http://dx.doi.org/10.1016/j.jdeveco.2005.04.003.

Franzen, A., Meyer, R., 2010. Environmental attitudes in cross-national perspective: a multilevel analysis of the issp 1993 and 2000. Eur Sociol Rev 26 (2), 219. http:// dx.doi.org/10.1093/esr/jcp018.

Frederick, S., Loewenstein, G., O'donoghue, T., 2002. Time discounting and time preference: a critical review. J Econ Lit 40 (2), $351-401$.

Fredriksson, P.G., Neumayer, E., 2013. Democracy and climate change policies: is history important? Ecol. Econ. 95, 11-19. http://dx.doi.org/10.1016/j.ecolecon. 2013.08.002.

Fredriksson, P.G., Neumayer, E., 2016. Corruption and climate change policies: do the bad old days matter? Environ. Resour. Econ. 63 (2), 451-469. http://dx.doi.org/ 10.1007/s10640-014-9869-6.

Fredriksson, P.G., Vollebergh, H.R.J., 2009. Corruption, federalism, and policy formation in the OECD: the case of energy policy. Public Choice 140 (1-2), 205-221. http://dx.doi.org/10.1007/s11127-009-9419-x.

Fredriksson, P.G., Wollscheid, J.R., 2014. Political institutions, political careers and environmental policy. Kyklos 67 (1), 54-73. http://dx.doi.org/10.1111/kykl. 12043.

Fredriksson, P.G., Wollscheid, J.R., 2015. Legal origins and climate change policies in former colonies. Environ. Resour. Econ. 62 (2), 309-327. http://dx.doi.org/10. 1007/s10640-015-9957-2.

Galor, O., Özak, Ö., 2016. The agricultural origins of time preference. Am. Econ. Rev. 106 (10), 3064-3103. http://dx.doi.org/10.1257/aer.20150020.

Galor, O., Özak, Ö., Sarid, A., 2016. Geographical origins and economic consequences of language structures.

Gay, V., Hicks, D.L., Santacreu-Vasut, E., 2016. Migration as a window into the coevolution between language and behavior. SSRN 2747153.

Gay, V., Hicks, D.L., Santacreu-Vasut, E., Shoham, A., 2017. Decomposing culture: an analysis of gender, language, and labor supply in the household. Rev. Econ. Househ. http://dx.doi.org/10.1007/s11150-017-9369-x.

Gelissen, J., 2007. Explaining popular support for environmental protection. Environ. Behav. 39 (3), 392-415. http://dx.doi.org/10.1177/0013916506292014.

Guin, B., 2015. Culture and household saving. Available at SSRN 2698872.

Gumperz, J.J., Levinson, S., 1996. Rethinking Linguistic Relativity. Studies in the Social and Cultural Foundations of Language 17 Cambridge University Press, Cambridge.

Hall, R.E., Jones, C.I., 1999. Why do some countries produce so much more output per worker than others?* Q. J. Econ. 114 (1), 83-116. http://dx.doi.org/10.1162/ 003355399555954.

Hicks, D.L., Hicks, J.H., Maldonado, B., 2016. Women as policy makers and donors: female legislators and foreign aid. Eur. J. Polit. Econ. 41, 46-60. http://dx.doi.org/ 10.1016/j.ejpoleco.2015.10.007.

Hicks, D.L., Santacreu-Vasut, E., Shoham, A., 2015. Does mother tongue make for women's work? linguistics, household labor, and gender identity. J. Econ. Behav. and Org. 110, 19-44. http://dx.doi.org/10.1016/j.jebo.2014.11.010.

Inglehart, R., 1995. Public support for environmental protection: objective problems and subjective values in 43 societies. PS: Pol. Sci. Pol. 28 (1), 57-72.

Joireman, J., Shaffer, M.J., Balliet, D., Strathman, A., 2012. Promotion orientation explains why future-oriented people exercise and eat healthy: evidence from the two-factor consideration of future consequences-14 scale. Personality Soc. Psychol. Bull. 38 (10), 1272-1287.

Kahn, M.E., 2002. Demographic change and the demand for environmental regulation. J. Policy Anal. Manage. 21 (1), 45-62. http://dx.doi.org/10.1002/pam.1039.

Kashima, E.S., Kashima, Y., 1998. Culture and language: the case of cultural dimensions and personal pronoun use. J. Cross Cult. Psychol. 29 (3), 461-486. http://dx. doi.org/10.1177/0022022198293005.

Kay, P., Regier, T., 2006. Language, thought and colour: recent developments. Trends Cogn. Sci. (Regul. Ed.) 10 (2), 51-54.

Keefer, P., 2012. Database of political institutions 2012. Computer file.

Kirby, K.N., Herrnstein, R., 1995. Preference reversals due to myopic discounting of delayed reward. Psychol. Sci. 6 (2), 83-89. 
Kleibergen, F., Paap, R., 2006. Generalized reduced rank tests using the singular value decomposition. J. Econ. 133 (1), 97-126. http://dx.doi.org/10.1016/j.jeconom. 2005.02.011.

La Porta, R., Lopez-de Silanes, F., Shleifer, A., 2008. The economic consequences of legal origins. J. Econ. Lit. 46 (2), $285-332$.

Lalev, E., Grinberg, M., 2006. Backward vs. Forward-oriented Decision Making in the Iterated Prisoners Dilemma: A Comparison between Two Connectionist Models. In: Butz, M.V., Sigaud, O., Pezzulo, G., Baldassarre, G. (Eds.), Anticipatory Behavior in Adaptive Learning Systems: From Brains to Invididual and Social Behavior. Springer, Heidelberg, pp. 345-364.

Levinson, S.C., 1996. Frames of reference and molyneux's question: crosslinguistic evidence. Language and space 109-169.

Levinson, S.C., Wilkins, D.P., 2006. Grammars of Space: Explorations in Cognitive Diversity. 6 Cambridge University Press, Cambridge.

Licht, A.N., Goldschmidt, C., Schwartz, S.H., 2007. Culture rules: the foundations of the rule of law and other norms of governance. J. Comp. Econ. 35 (4), 659-688. http://dx.doi.org/10.1016/j.jce.2007.09.001.

Lucy, J.A., 1997. Linguistic relativity. Ann. Rev. Anthropol. 26, 291-312.

Marshall, M.G., Gurr, T.R., Jaggers, K., 2016. Polity IV dataset. Computer file.

Mavisakalyan, A., 2015. Gender in language and gender in employment. Oxford Dev. Stud. 43 (4), 403-424. http://dx.doi.org/10.1080/13600818.2015.1045857.

Mavisakalyan, A., Weber, C., 2017. Linguistic structures and economic outcomes. J. Econ. Surv. 00 (0), 1-24.

Messick, D.M., McClintock, C.G., 1968. Motivational bases of choice in experimental games. J. Exp. Soc. Psychol. 4 (1), 1-25.

Murdoch, J.C., Sandler, T., 1997. The voluntary provision of a pure public good: the case of reduced cfc emissions and the montreal protocol. J. Public Econ. 63 (3), 331-349. http://dx.doi.org/10.1016/S0047-2727(96)01598-8.

Neumayer, E., 2002. Does trade openness promote multilateral environmental cooperation? World Econ. 25 (6), 815-832. http://dx.doi.org/10.1111/1467-9701. 00464.

Neumayer, E., 2003. Are left-wing party strength and corporatism good for the environment? evidence from panel analysis of air pollution in oecd countries. Ecol. Econ. 45 (2), 203-220. http://dx.doi.org/10.1016/S0921-8009(03)00012-0.

Neumayer, E., 2004. The environment, left-wing political orientation and ecological economics. Ecol. Econ. 51 (3), 167-175. http://dx.doi.org/10.1016/j.ecolecon. 2004.06.006.

Nurse, D., 2008. Tense and Aspect in Bantu. Oxford University Press, Oxford.

Osborne, M.J., Slivinski, A., 1996. A model of political competition with citizen-candidates. Q. J. Econ. 111 (1), 65-96. http://dx.doi.org/10.2307/2946658.

Oster, E., 2016. Unobservable selection and coefficient stability: theory and evidence. J. Bus. Econ. Stat. 0 (0), 1-18. http://dx.doi.org/10.1080/07350015.2016. 1227711.

Parks, C.D., 2015. Determinants of Cooperation in Social Dilemmas. In: Graziano, W.G., Schroeder, D.A. (Eds.), The Oxford Handbook of Prosocial Behavior. Oxford University Press, Oxford, pp. 524-547.

Porta, R.L., Lopez-de Silanes, F., Shleifer, A., Vishny, R.W., 1998. Law and finance. J. Pol. Econ. 106 (6), $1113-1155$.

Ramsey, F.P., 1928. A mathematical theory of saving. Econ. J. 38, 543-549.

Roberts, S.G., Winters, J., Chen, K., 2015. Future tense and economic decisions: controlling for cultural evolution. PLoS ONE 10 (7), 1-46. http://dx.doi.org/10.1371/ journal.pone.0132145.

Santacreu-Vasut, E., Shenkar, O., Shoham, A., 2014. Linguistic gender marking and its IB ramifications. J. Int. Bus. Stud. 45 (9), $1170-1178$.

Santacreu-Vasut, E., Shoham, A., Gay, V., 2013. Do female/male distinctions in language matter? evidence from gender political quotas. Appl. Econ. Lett. 20 (5), 495-498. http://dx.doi.org/10.1080/13504851.2012.714062.

Scholz, B.C., Pelletier, F.J., Pullum, G.K., 2016. Philosophy of Linguistics. In: Zalta, E.N. (Ed.), The Stanford Encyclopedia of Philosophy, Winter 2016 edition. Metaphysics Research Lab, Stanford University.

Slobin, D.I., 2003. Language and Thought Online: Cognitive Consequences of Linguistic Relativity. In: Gentner, D., Goldin-Meadow, S. (Eds.), Language in mind: Advances in the study of language and thought. MIT press, Cambridge, pp. 157-192.

Solnick, J.V., Kannenberg, C.H., Eckerman, D.A., Waller, M.B., 1980. An experimental analysis of impulsivity and impulse control in humans. Learn. Motiv. 11 (1), 61-77.

Steves, F., Treisman, D., Teytelboyn, A., 2011. The Political Economy of Climate Change Policy in the Transition Region. The low carbon transition. EBRD and The Grantham Research Institute on Climate Change and the Environment, LSE.

Strathman, A., Gleicher, F., Boninger, D.S., Edwards, C.S., 1994. The consideration of future consequences: weighing immediate and distant outcomes of behavior. J. Pers. Soc. Psychol. 66 (4), 742-752.

Su, X., Tang, Y., Xu, B., 2016. Reward-timing uncertainty, languages, and r\&d investment. Unpublished manuscript.

Sutter, M., Angerer, S., Rützler, D., Lergetporer, P., 2015. The effect of language on economic behavior: experimental evidence from children's intertemporal choices. IZA Discussion Paper 9383.

Tabellini, G., 2008. Presidential address institutions and culture. J. Eur. Econ. Assoc. 6 (2-3), 255-294. http://dx.doi.org/10.1162/JEEA.2008.6.2-3.255.

Tonn, B.E., Waidley, G., Petrich, C., 2001. The ageing us population and environmental policy. J. Environ. Plann. Manage. 44 (6), 851-876. http://dx.doi.org/10. $1080 / 09640560120087606$.

Van Lange, P., Balliet, D.P., Parks, C.D., van Vugt, M., 2014. Social dilemmas: Understanding human cooperation. Oxford University Press, New York.

Van Lange, P.A., 1999. The pursuit of joint outcomes and equality in outcomes: an integrative model of social value orientation. J. Pers. Soc. Psychol. 77 (2), 337-349.

Winawer, J., Witthoft, N., Frank, M.C., Wu, L., Wade, A.R., Boroditsky, L., 2007. Russian blues reveal effects of language on colour discrimination. Proc. Natl. Acad. Sci. 114 (19), 7780-7785.

World Bank, 2016. World development indicators database. Computer file.

Yamagishi, T., 2011. Trust: The Evolutionary Game of Mind and Society. Springer, Tokyo. 